This is a self-archived version of an original article. This version may differ from the original in pagination and typographic details.

Author(s): Portalone, Gustavo; Rissanen, Kari

Title: Multifacial Recognition in Binary and Ternary Cocrystals from 5-Halouracil and Aminoazine Derivatives

Year: 2018

Version: Accepted version (Final draft)

Copyright: (c) 2018 American Chemical Society

Rights: In Copyright

Rights url: http://rightsstatements.org/page/InC/1.0/?language=en

Please cite the original version:

Portalone, G., \& Rissanen, K. (2018). Multifacial Recognition in Binary and Ternary Cocrystals from 5-Halouracil and Aminoazine Derivatives. Crystal Growth and Design, 18(10), 5904-5918. https://doi.org/10.1021/acs.cgd.8b00662 
Subscriber access provided by JYVASKYLAN UNIV

\section{Article}

\section{Multifacial Recognition in Binary and Ternary Cocrystals from 5-Halouracil and Aminoazine Derivatives}

Gustavo Portalone, and Kari Rissanen

Cryst. Growth Des., Just Accepted Manuscript • DOI: 10.1021/acs.cgd.8b00662 • Publication Date (Web): 04 Sep 2018

Downloaded from http://pubs.acs.org on September 6, 2018

\section{Just Accepted}

"Just Accepted" manuscripts have been peer-reviewed and accepted for publication. They are posted online prior to technical editing, formatting for publication and author proofing. The American Chemical Society provides "Just Accepted" as a service to the research community to expedite the dissemination of scientific material as soon as possible after acceptance. "Just Accepted" manuscripts appear in full in PDF format accompanied by an HTML abstract. "Just Accepted" manuscripts have been fully peer reviewed, but should not be considered the official version of record. They are citable by the Digital Object Identifier (DOI®). "Just Accepted" is an optional service offered to authors. Therefore, the "Just Accepted" Web site may not include all articles that will be published in the journal. After a manuscript is technically edited and formatted, it will be removed from the "Just Accepted" Web site and published as an ASAP article. Note that technical editing may introduce minor changes to the manuscript text and/or graphics which could affect content, and all legal disclaimers and ethical guidelines that apply to the journal pertain. ACS cannot be held responsible for errors or consequences arising from the use of information contained in these "Just Accepted" manuscripts. 


\title{
Multifacial Recognition in Binary and Ternary Cocrystals from 5-Halouracil and Aminoazine Derivatives
}

\begin{abstract}
Gustavo Portalone ${ }^{1, *}$ and Kari Rissanen ${ }^{2, *}$
${ }^{1}$ Department of Chemistry, 'La Sapienza' University of Rome, 00185 Rome, Italy.

${ }^{2}$ University of Jyväskylä, Department of Chemistry, P.O. Box. 35, FI- 40014 Jyväskylä, Finland

ABSTRACT A systematic analysis using single crystal X-ray diffraction was performed to explore the role exerted by potential intercomponent proton-transfer reactions in the supramolecular structures of A-B cocrystals formed by 5-haloderivatives of uracil (A) coupled with 2-aminoadenine simulants (aminoazines, B). Twelve new heterodimers were synthesized in different stoichiometry and cocrystallized by solvent co-grinding followed by solution crystallization. In the binary cocrystals, uracil or 1-methyluracil with halide modification at the 5 position $(\mathrm{F}, \mathrm{Cl}, \mathrm{Br}$, I) were coupled with aminoaromatic $\mathrm{N}$-heterocycles (melamine, 2,4,6-triaminopyrimidine, 2,6-diaminopyridine) as multivalent site for pyrimidine nucleobase recognition. The crystallographic analysis showed that, next to the expected neutral three-point hydrogen bonds (TPI), ionized TPI, favored by A $\rightarrow$ B proton transfer, can be used for $W C$ multifacial recognition. Noteworthy, the formation of the charged TPI, which depends on the acid/base properties of the components, takes always place between the more acidic site of the 5halonucleobases (N3 atom) and the more basic site (imino $\mathrm{N}$ atom) of 2,4,6-triaminopyrimidine or 2,6diaminopyridine, and melamine recognition unit results to be insufficiently basic to accept a proton. The general ability of pyrimidine nucleobases to provide electron donating groups to halogen bonding has been confirmed in seven cocrystals containing the 5-chloro, 5-bromo or 5-iododerivatives coupled with melamine or 2,4,6-triaminopyrimidine. Considerations of the relative acidities of coformers $\mathrm{A}$ and of the relative basicities of coformers B allowed us to design and characterize by single-crystal X-ray diffraction the first ternary pyrimidine nucleobase-containing cocrystal based on the JANUS-WEDGE concept: the nucleobase-Janus-nucleobase (1:1:1) triad showing a 2,4,6-triamino pyrimidine molecule wedged via neutral and ionized TPI between the 5-fluorouracil/1-methyluracil pair in reverse $W C$ fashion.
\end{abstract}

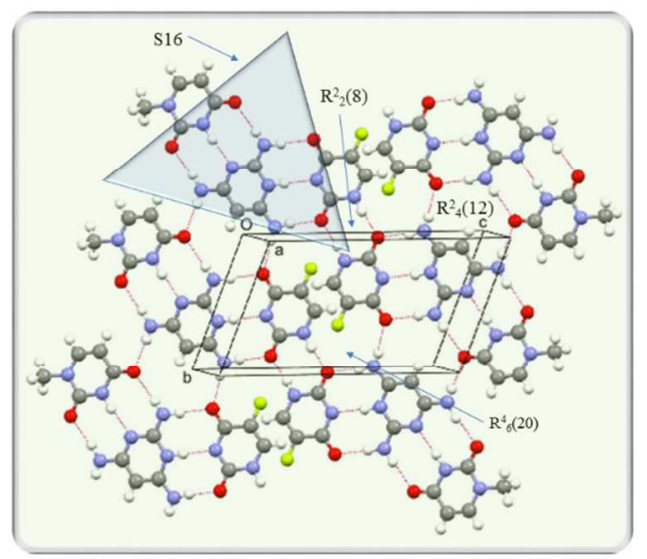




\title{
Multifacial recognition in Binary and Ternary
}

\section{Cocrystals from 5-Halouracil and Aminoazine}

\section{Derivatives}

\author{
Gustavo Portalone ${ }^{1, *}$ and Kari Rissanen ${ }^{2, *}$ \\ ${ }^{1}$ Department of Chemistry, 'La Sapienza' University of Rome, 00185 Rome, Italy. \\ ${ }^{2}$ University of Jyväskylä, Department of Chemistry, P.O. Box. 35, FI- 40014 Jyväskylä, Finland \\ KEYWORDS: 5-haloluracils; non-canonical nucleobases; aminoazines; crystal engineering; \\ binary cocrystals; ternary cocrystals; JANUS-WEDGE cocrystal; halogen bonding; hydrogen \\ bonding.
}




\section{ABSTRACT}

A systematic analysis using single crystal X-ray diffraction was performed to explore the role exerted by potential intercomponent proton-transfer reactions in the supramolecular structures of A-B cocrystals formed by 5-haloderivatives of uracil (A), coupled with 2-aminoadenine simulants (aminoazines, B). Twelve new heterodimers were synthesized in different stoichiometry and cocrystallized by solvent co-grinding followed by solution crystallization. In the binary cocrystals, uracil or 1-methyluracil with halide modification at the 5 position $(\mathrm{F}, \mathrm{Cl}$, $\mathrm{Br}, \mathrm{I})$ were coupled with amino-aromatic $N$-heterocycles (melamine, 2,4,6-triaminopyrimidine, 2,6-diaminopyridine) as multivalent site for pyrimidine nucleobase recognition. The crystallographic analysis showed that, next to the expected neutral three-point hydrogen bonds (TPI), ionized TPI, favored by $\mathrm{A} \rightarrow \mathrm{B}$ proton transfer, can be used for $W C$ multifacial recognition. Noteworthy, the formation of the charged TPI, which depends on the acid/base properties of the components, takes always place between the more acidic site of the 5halonucleobases (N3 atom) and the more basic site (imino $\mathrm{N}$ atom) of 2,4,6-triaminopyrimidine or 2,6-diaminopyridine, and melamine recognition unit results to be insufficiently basic to accept a proton. The general ability of pyrimidine nucleobases to provide electron donating groups to halogen bonding has been confirmed in seven cocrystals containing the 5-chloro, 5-bromo or 5iododerivatives coupled with melamine or 2,4,6-triaminopyrimidine. Considerations of the relative acidities of coformers $\mathrm{A}$ and of the relative basicities of coformers $\mathrm{B}$ allowed us to design and characterize by single-crystal X-ray diffraction the first ternary pyrimidine nucleobase-containing cocrystal based on the JANUS-WEDGE concept: the nucleobase-Janusnucleobase (1:1:1) triad showing a 2,4,6-triamino pyrimidine molecule wedged via neutral and ionized TPI between the 5-fluorouracil/1-methyluracil pair in reverse $W C$ fashion. 


\section{INTRODUCTION}

Naturally occurring modified non-canonical nucleobases, next to the five canonical nucleobases, extend the chemical information content of DNA and RNA, ${ }^{1}$ but their role in regulating the basic functions in a cell is still largely unexplored. ${ }^{2}$ Among chemical variations of nucleic acids that allow chemists to harness and reprogram the cellular machinery, the diversification of nucleobase structure due to the halogen substitution in uracil and the amino substitution in adenine creates additional DNA/RNA base pairs, modifies the thermal stability, and increases the specificity of the hosting duplexes. ${ }^{3-6}$ Indeed, from one side recently several studies have been focused on the importance of halogen bonding (XB) in directing the conformation of DNA containing halonucleobases. ${ }^{7-10}$ From the other side, the ability of 2-aminosubstituted adenine to form $A D A / D A D$ hydrogen bonding patterns (three-point interactions, TPI) significantly increases the base-pair stability retaining the structural integrity of the nucleic acid nanostructure. ${ }^{11}$ Thus, it has been used for chemical fine-tuning of artificial DNA and RNA in synthetic biology. ${ }^{12-15}$

TPI heterosynthon $\left(\mathrm{R}_{2}^{2}(12)\right.$ graph-set motif) ${ }^{16,17}$ is very robust and reliable, and has been used in the construction of supramolecular assemblies since many years. ${ }^{18}$ Rods, tapes and cyclic hexamers (rosettes) have been prepared using this synthon in the $A D A / D A D$ complexes of cyanuric acid and melamine with a (1:1) stoichiometry. ${ }^{19}$ It has been shown that the layered structure of hexamers of melamine-cyanuric acid complexes derives from the ability of threefold symmetric heterocycles to polymerize via hydrogen bonding (HB) formation. ${ }^{20,21}$ Nevertheless, it is still unclear if sym-triaminotriazine coupled with molecules of lower symmetry as 5-halouracils would display a similar behavior. 
At the moment, although molecular complexes showing neutral TPI, i.e. not involving ionized groups, as well as $\mathrm{XB}$ interactions have been described since many years, ionized TPI and halogen bonding in cocrystals containing halouracils and amino-substituted aromatic $N$ heterocycles (aminoazine) are not well studied in the solid state. This is somewhat surprising, as pyrimidine halonucleobases are weak dibasic acids dissociating in water via $\mathrm{N}_{\text {ring }}-\mathrm{H}$ bonds and are naturally rich in electronegative atoms (oxygens), which make them potential X-bond donors/acceptors. A search with the Cambridge Structural Database (CSD, version 5.39 updated to May 2018) ${ }^{22}$ for supramolecular systems showing Watson-Crick (WC) interfacial recognition in crystal structures containing uracils coupled with aminoazine units having donor/acceptor sites potentially available for single or multiple TPI returned 50 hits. Out of these hits, 34 contained one TPI, and only cocrystals where the aminoazine unit was melamine showed bifacial (6 hits) and trifacial TPI (2 hits) (Scheme 1).

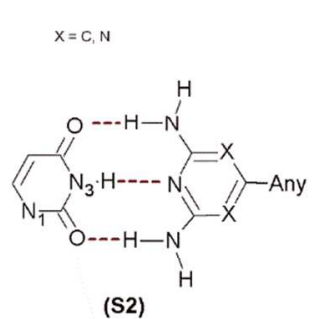

(S2)
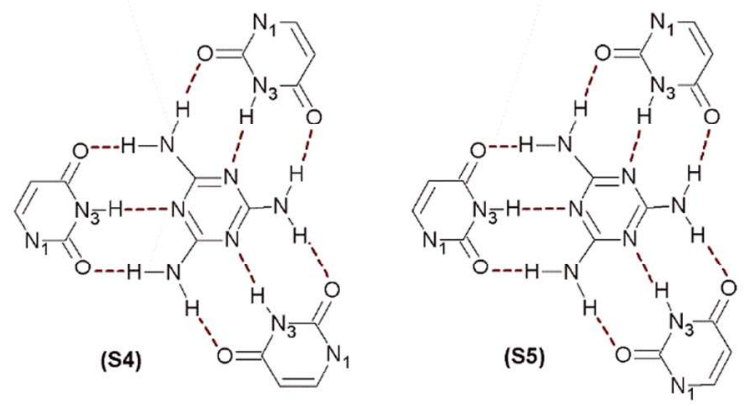

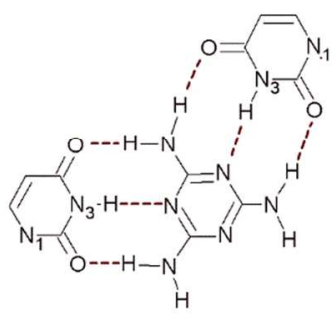

(S3)

Scheme 1 Neutral TPI utilized for mono (S1), bi (S2 and S3) and trifacial (S4 and S5) recognition in structures containing complexes of uracils with aminoazines. 
From this survey, only 8 hits contained halouracils. Three of these hits contained 5-halouracils as cocrystals: $\quad$ 1-methyl-5-iodouracil/9-ethyl-2,6-diaminopurine $\quad(1: 1), \quad$ MIUDAP10, ${ }^{23}$ 5fluorouracil/melamine (1:1), OPOVAS, and 5-fluorouracil/melamine pentahydrate (4:2), OPOTUK. ${ }^{24}$ Interestingly, in the remaining 5 hits containing uracil ring with halogen substitution at the 6 position, three corresponded to molecular salts showing 6-chlorouracil deprotonated at the N1 position: 6-chlorouracil/2,4,6-triaminopyrimidine $N$-methylpyrrolidin-2-one solvate monohydrate (1:1), ZUDSEY, 6-chlorouracil/2,4-diamino-6-methyl-1,3,5-triazine (1:1) $N, N$ dimethyl acetamide solvate, ZUDSOI, and 6-chlorouracil/2,4-diamino-6-methyl-1,3,5-triazine (1:1) N,N-dimethylformamide solvate monohydrate, ZUDSUO. ${ }^{25}$ All the 8 hits but ZUDSEY showed non-canonical base-pairing through neutral TPI. Adopting a cutoff value of 0.9 for the interaction ratio $R_{\mathrm{XB}},{ }^{26}$ the ratio between the $\mathrm{X}^{\cdots} \mathrm{A}(\mathrm{A}=$ acceptor $)$ contacts with linear $\mathrm{C}-\mathrm{X} \cdots \mathrm{A}$ disposition (bond angle $>155^{\circ}$ ) and the sum of van der Waals (vdW) radii, ${ }^{27}$ of the 8 unique hits only MIUDAP10, ZUDTAV and ZUDTAV01 (6-chlorouracil/2-chloro-4,6-diamino-1,3,5triazine (1:1) N,N-dimethyl formamide solvate and 6-chlorouracil/2-chloro-4,6-diamino-1,3,5triazine (2:2) $\mathrm{N}, \mathrm{N}$-dimethyl formamide disolvate, respectively $)^{25}$ showed crystallographic evidence of the formation of weak XBs.

In this context, because of our long-term interest in the potential of pyrimidine nucleobases for crystal engineering strategies underpinned by multiple hydrogen bonds, ${ }^{28-32}$ and our earlier experience with binary systems showing XB via alternative donors (i.e. halogen atom not polarized by fluorine), ${ }^{33-36}$ we were interested to investigate the supramolecular architectures in biological systems, i. e. in cocrystals formed by haloderivatives of uracil coupled with aminoaromatic $N$-heterocycles, where the ability to distinguish between base pairing is offered by A $\rightarrow$ 
B proton-transfer reactions. Consequently, we focused our attention on a systematic XRD analysis of A-B cocrystals containing in different stochiometric ratios uracil or 1-methyluracil derivatives with halide modification at the 5 position (coformer A), coupled with an aminoderivative of aromatic $N$-heterocycles (coformer B) (Scheme 2).
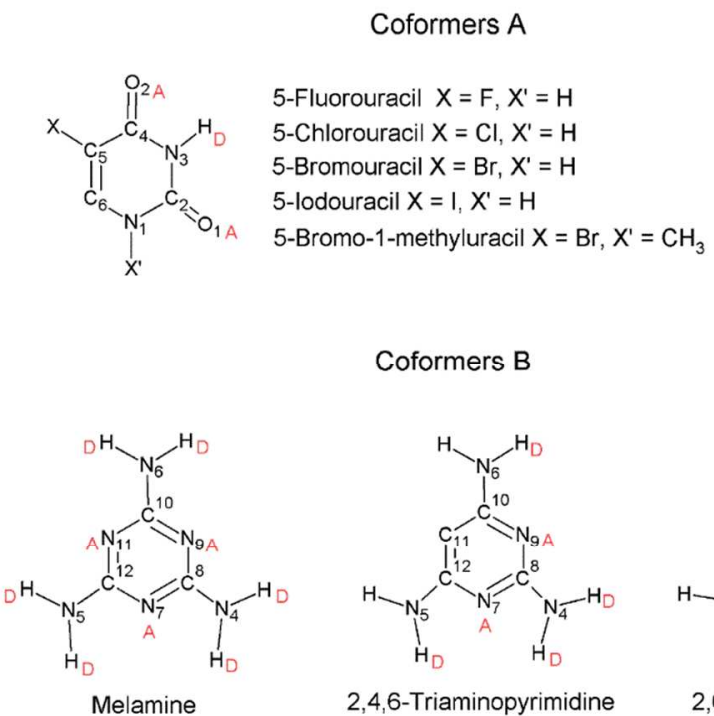

Coformers B

Scheme 2 Coformers forming the A-B cocrystals investigated in this study and the adopted atom-labeling scheme. For both coformers, the donor/acceptor sites potentially available for TPI are shown in red.

In these binary cocrystals, aminoazines provide up to three sites for uracil recognition as $W C$ pairing should take place between the $A D A$ face of coformer A and the $D A D$ face(s) of coformer $\mathrm{B}$ through the formation of the neutral $(A D A / D A D)$ TPI. Moreover, depending on the basicity of aminoazines and the acidity of halonucleobases, deprotonation at the N1 or N3 sites of halouracils can lead to the formation of ion-paired dimers. However, only the $\mathrm{N}^{-}$atom can interact with the imino $\mathrm{N}^{+}$atom of aminoazines for the formation of the more effective ionized 
$(A A A / D D D)$ TPI in ion-paired dimers. ${ }^{37-39}$ and the charged TPI formation should be a driving force for proton dissociation from the $\mathrm{N} 3$ atom.

Apart from these considerations, the chosen systems should also offer the opportunity of studying the influence exerted by halogen atoms engaged in possible XB "lateral" to TPI. Out of 15 possible combinations, 12 yielded new binary cocrystals. The design of these binary cocrystals was realized from consideration of the following points.

Among pyrimidine halonucleobases, 5-haloderivatives deserve special attention, because their structure is like that of thymine (5-methyluracil) by exchanging the methyl group attached at the $\mathrm{C} 5$ atom with the halogen atom. ${ }^{40,41}$ Consequently, 5-halouracils may be incorporated into DNA in vivo, and this incorporation into DNA can lead to mutagenesis, cytotoxicity, and carcinogenesis. $^{42-44}$ In recent years, as the substitution of thymine by 5-halouracil in DNA leads to greater sensitivity to ionizing radiation without changing the normal gene expression in the unradiated cells, these non-canonical nucleobases have been proposed for the development of new therapeutic and biotechnological agents. ${ }^{45,46}$

The 5-halouracils are particularly attractive for $W C$ interfacial recognition assisted by proton transfer reactions. It has been reported previously that pyrimidine halonucleobases are weak dibasic acids, and their dissociation in water is very important for nucleic acids, as it affects the base-pair stability. ${ }^{47}$ Halogen substitution at the 5 position in uracil can change the electronic properties of pyrimidine bases, present as diketo tautomers under physiological conditions, and the $\mathrm{p} K_{\mathrm{a}}$ in water decreases in the order $\mathrm{I}>\mathrm{Br}>\mathrm{Cl}>\mathrm{F}(8.13,7.91,7.92$ and 7.93, respectively) compared to that of uracil (9.42). ${ }^{48-51}$ Theoretical and experimental investigations have been used to distinguish in the heterocyclic ring the two sites (N1 and N3) for ionization in 
water. Indeed, the existence of a 5-substituted uracil ring with a negative charge on N3 is of great interest, because as already mentioned such species are implicated in the mechanism by which 5halonucleosides are incorporated into DNA. From theoretical studies, it was shown that for 5fluorouracil in the gas phase the enthalpy of deprotonation from $\mathrm{N} 1$ is $10-12 \mathrm{kcal} / \mathrm{mol}$ is more favorable than from N3. However, the enthalpy of solvation of the $\mathrm{N}^{-}$is $13-14 \mathrm{kcal} / \mathrm{mol}$ is less favorable than for the $\mathrm{N}^{-}$, and the aqueous-phase dipole moments of the $\mathrm{N}^{-}$and the $\mathrm{N}^{-}{ }^{-}$species are 3.95 and $12.15 \mathrm{D}$, respectively. Thus, in 5-fluorouracil and in 5-bromouracil the calculated $\mathrm{p} K_{\mathrm{a}}$ value in water of the $\mathrm{N} 3$ site results lower than that for the $\mathrm{N} 1$ site by $1-2$ units. ${ }^{52,54}$ The competition between the two sites for ionization in 5-halouracils has been analyzed by different experimental techniques in solution. The UV spectra of the monosodium salt of 5-fluorouracil showed that in water and in aqueous dioxane the ratio of the $\mathrm{N} 1^{-} / \mathrm{N}^{-}$species is $1: 2$ and $3: 1$, respectively. ${ }^{55}$ NMR spectra of 5-fluoro, 5-chloro and 5-bromouracil in alkaline medium in water and in DMSO confirmed that anion containing the $\mathrm{N}^{-}$species is predominant in water solvent. ${ }^{56,57}$ NMR spectra in buffer solution showed that the 5-chlorouracil-guanine base pair undergoes a pH-dependent structural change assuming an ionized base pair configuration, and the ionization of the $\mathrm{N} 3$ atom in 5-chlorouracil promotes mispair formation. ${ }^{58}$ Concerning the solid state, a survey of the Cambridge Structural Database (CSD, version 5.39 updated to May $2018)^{22}$ for crystal structures containing the uracil moiety (excluding metallic elements) gave 1282 hits. Out of these hits, 19 showed the uracil moiety ionized at the N1 position and only one, IADXUR10, 5-iodo-5'-amino-2',5'-dideoxyuridine, which is present in the crystal in the zwitterionic form, showed the occurrence in the uracil ring of the N3 atom ionized. ${ }^{59}$

To decades ago, it was hypothesized that the availability of the imide carbonyl acceptor sites for hydrogen bonds affords a handle to control the stoichiometry and structure by increasing 
steric hindrance in TPI melamine-imide complexes. ${ }^{60}$ It was shown that, for melamine engaged in TPI with imides, the stoichiometry is (1:1) for melamine-succinimide (all acceptor sites used), (1:2) for melamine-glutarimide (one acceptor site unused) and (1:3) for melamine-1-Npropylthymine (two acceptor sites unused). Thus, coformers A offer the possibility to test the proposed hypothesis, having one of the two carbonyl acceptor sites of the imide moieties masked by substituents in the 5 position. This choice has been extended to 5-halo-1-methyluracils, which can be considered simple models of 5-halouridine, as they show both the carbonyl acceptor sites of the imide moieties masked by substituents in the 1-5 positions. In the ahead discussions, the following abbreviations Fura, Clura, Brura, Iura, Brmura and Mura are used for 5-fluorouracil, 5chlororouracil, 5-bromorouracil, 5-iodorouracil, 5-bromo,1-methyluracil and 1-methyluracil, respectively.

Coformers B (2,4,6-triamino-1,3,5-triazine, melamine, Mel; 2,4,6-triaminopyrimidine, Tap; 2,6-diaminopyridine, Dap), are weak organic bases structurally related to 2-aminoadenine, and have been selected among shape-mimicking nucleobases which can realize, via interfacial recognition, specific supramolecular interactions in $W C$ fashion. Coformers B show different sites available for single or multiple protonation. A search for crystal structures containing the protonated form of Mel, Tap and Dap with the Cambridge Structural Database (CSD, version 5.39 updated to May 2018) $)^{22}$ gave 317 hits. Out of these hits, 283 showed monoprotonation at one of the $\mathrm{N}_{\text {ring }}$ atom, 26 diprotonation at two $\mathrm{N}_{\text {ring }}$ atoms, and only 8 were protonated at the amino group. Thus, due to the delocalization of electrons from the $\mathrm{N}$ atom of the $\mathrm{NH}_{2}$ moiety to the aminoazine aromatic ring, these weak bases can be typically protonated at one of the imino $\mathrm{N}$ atoms in medium/strong acidic media. ${ }^{61-67}$ Interestingly, the basicity of coformers $\mathrm{B}$ is significantly increased by replacing the pyridine ring nitrogen atoms with the $\mathrm{CH}$ moiety (first 
$\mathrm{p} K_{\mathrm{a}}$ [conjugate acid of base $]=5.0,6.8$ and 7.3 in water for Mel, Tap and Dap, respectively). ${ }^{68-70}$ Consequently, their abilities to act as hydrogen bond acceptors can vary, and can be used for selecting the intermolecular reactivity between the A and B coformers.

Among different synthetic strategies adopted in the design of ternary cocrystals, ${ }^{71-84}$ it has been shown that stronger acidic sites interacts with the more basic hydrogen bond acceptor, while the weaker acid engages in hydrogen bonding with the less basic hydrogen bond acceptor. ${ }^{85,86}$ Following the aforementioned guidelines, considerations of the relative acidities of 5-halouracils and of the relative basicities of aminoazines allowed us to choose the combination able to realize the first ternary cocrystal based on the JANUS-WEDGE concept: ${ }^{87}$ one Janus base able for bifacial recognition (Tap) wedged between two DNA pyrimidine nucleobases differing in the acidic properties. This result gives important insight in the potential for recognition of mismatched nucleobase pairs as versatile tool in the emerging area of synthetic biology. ${ }^{88-92}$ 


\section{EXPERIMENTAL SECTION}

\section{Synthesis and crystallization}

The 5-halouracils, 5-bromo-1-methyluracil and 1-methyluracil, Mel (melamine, 2,4,6-triamino1,3,5-triazine), Tap (2,4,6-triaminopyrimidine) and Dap (2,6-diaminopyridine) were purchased from Aldrich (98-99+\% purity) and were subjected to further purification by successive sublimation under reduced pressure. Reagent grade solvents and bidistilled water were used as received.

The same crystallization method was used for all binary and ternary cocrystals. Equimolecular amounts $(1: 1$ or $1: 1: 1,0.1 \mathrm{mmol})$ of each pure compound were taken in an agate mortar and pestle and then liquid $\left(\mathrm{H}_{2} \mathrm{O}\right.$ or DMF) assisted co-grinding was performed on each mixture. Crystallization of ground powders were adjusted in a set of different solvents (or mixture of solvents). The resulting solutions $(1-2 \mathrm{ml})$ were heated at $70^{\circ} \mathrm{C}$, stirred for $6 \mathrm{~h}$ under reflux and then cooled to room temperature and filtered. The best crystals were obtained from slow room-temperature evaporation of water, $\mathrm{DMF}$ and $\mathrm{DMF} / \mathrm{H}_{2} \mathrm{O}(1: 1)$ solutions after one-two weeks. Any attempts to produce satisfactory quality crystals of FuraTap and CluraDap, as well as A-B cocrystals containing 5-haloderivatives of 1-methyluracil other than 5-bromo-1methyluracil, by repeating the crystallization conditions using different solvents, or mixtures of solvents in different ratios, were unsuccessful.

\section{X-ray Crystallography}

Crystals data, data collection and structure refinement details are summarized in Tables 1-4. The intensity data were collected using Oxford Diffraction Xcalibur S CCD diffractometer with graphite-monochromated Mo Ka radiation $(\lambda=0.71069 \AA)$ at room temperature. Data collection, 
integration and absorption corrections were performed using the CrysAlisPro software package. ${ }^{93}$ Solution, refinement and analysis of the structures were done using the programs integrated in the WinGX system. ${ }^{94}$

The crystal structures were solved by direct methods using SIR $2004^{95}$ and refined by the full-matrix least-squares method based on $F^{2}$ using SHELXL-2014/7. ${ }^{96}$ For all structures, nonhydrogen atoms were refined anisotropically. The hydrogen atoms were found from the difference Fourier map and refined freely. Carbon-bound $\mathrm{H}$ atoms were placed in calculated positions $\left[\mathrm{C}-\mathrm{H}=0.97 \AA, \mathrm{U}_{\text {iso }}(\mathrm{H})\right.$ values equal to $1.2 \mathrm{U}_{\mathrm{eq}}(\mathrm{C})$ for aromatic or $1.5 \mathrm{U}_{\text {eq }}(\mathrm{C})$ for methyl $\mathrm{H}$ atoms] as riding atoms. Free rotation about the local threefold axis was then allowed for all methyl groups. Geometrical calculations were performed using PLATON ${ }^{97}$ within WINGX and all figures were prepared with the Mercury 3.9 program package. ${ }^{98}$ Difference Fourier maps were computed using Platon. For cocrystals showing $\mathrm{N}^{+\cdots} \mathrm{H}^{\cdots} \mathrm{N}^{-}$hydrogen bond, difference Fourier maps were calculated without the hydrogen atoms involved. In BruraTap, our attempts to localize the $\mathrm{H}$ atoms for $\mathrm{O} 3{ }_{\mathrm{W}}$ failed as there were no significant peaks in the difference Fourier maps.

The IuraTap structure shows disordered iodine atom in two positions. BrmuraMel and BrmuraTap structures exhibit coformers A disordered over a pseudo-mirror along the N3 and C6 atoms perpendicular to the molecular plane. The disorder was modelled over two sites, with the aid of constraints on occupancy factors, and the ratio between major-/minor-occupied site was about 5:1, 3:1 and 6:1, respectively. In BrmuraMel, BruraTap, BrmuraTap, IuraDap and BrmuraDap free refinement of positional coordinates of atoms of the amino groups resulted in unsatisfactory wide range of $\mathrm{N}-\mathrm{H}$ distances. Consequently, these bond lengths were restrained to $0.86 \AA$. 


\section{RESULTS AND DISCUSSION}

The schematic representations of the different types of ionized/neutral TPI observed in this work are summarised in Scheme 3.

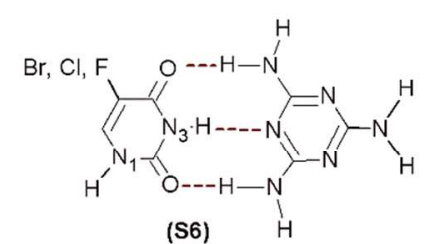

(S6)

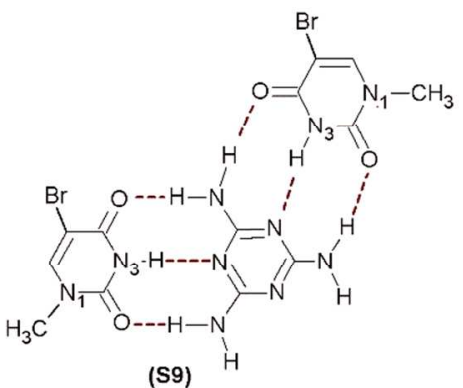

(S9)

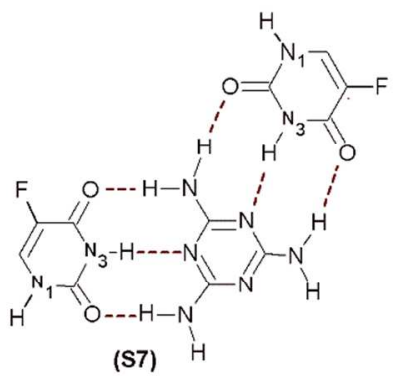

(S7) $\mathrm{H}$
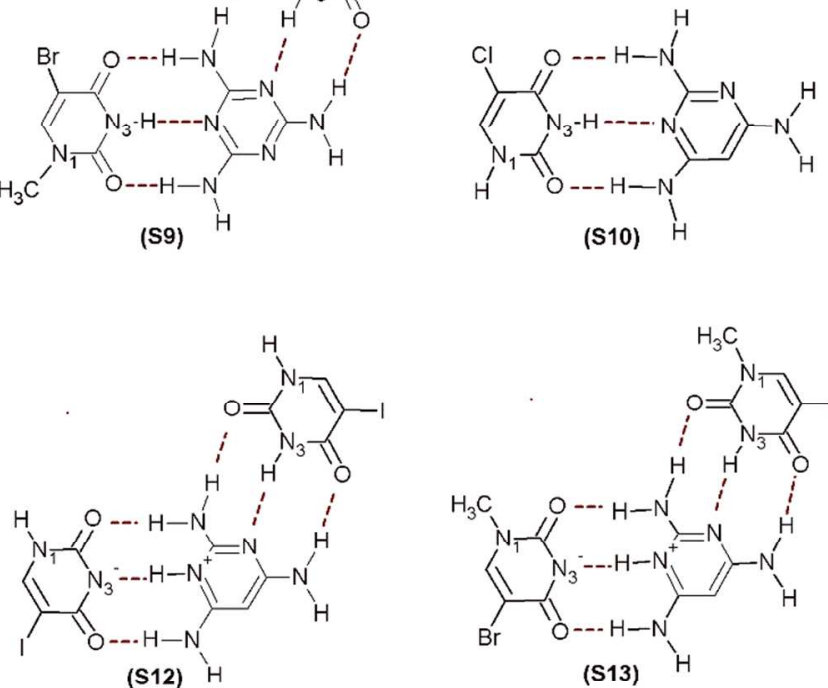

(S12) $\mathrm{H}$

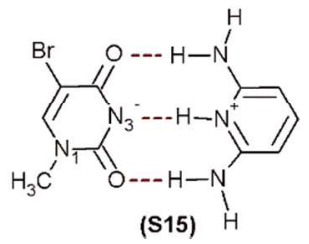

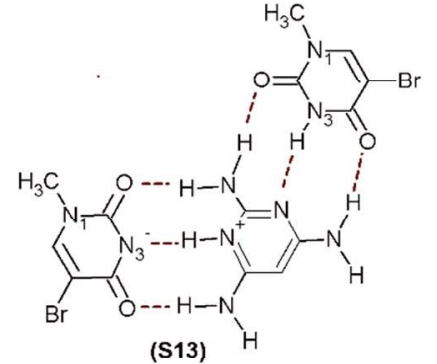

(S13)

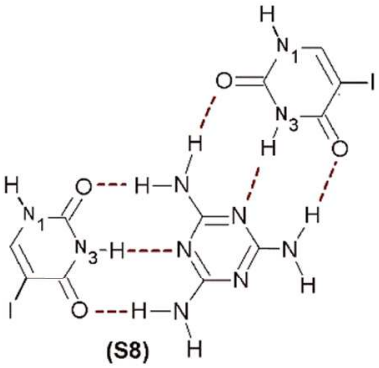

(S8) $\quad H$

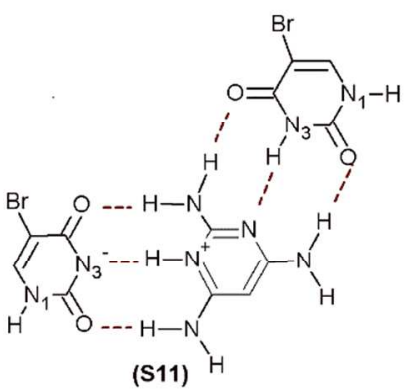

(S11) $\mathrm{H}$

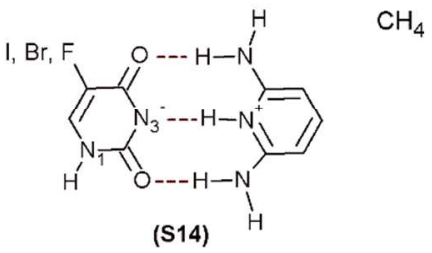

Scheme 3 Depictions of ionized/neutral TPI used for mono and bifacial recognition in the binary and ternary cocrystals investigated in this study. 


\section{A-B cocrystals with 2,4,6-triamino-1,3,5-triazine (Melamine, Mel) as coformer B}

Previous crystallographic studies have been reported for (1:1) anhydrous 5fluorouracil/melamine (OPOVAS) and (4:2) pentahydrate 5-fluorouracil/melamine (OPOTUK) forms. ${ }^{24}$ OPOVAS crystallizes in the monoclinic space group $C 2 / c$, and the asymmetric unit consists of a coplanar $W C$ pair formed by a molecule of Fura and another of Mel. In the crystal structure, Mel is engaged with Fura through TPI on one of its $W C$ faces showing monofacial recognition via the S6 synthon. Hydrogen-bonded heterodimeric synthons of $\mathrm{R}_{2}^{2}(8)$ graph-set motif are formed by $\mathrm{N}-\mathrm{H}^{\cdots} \mathrm{O}$ interactions with the $\mathrm{N}$ 1,2-oxo face of a second Fura molecule. These alternating patterns of TPI interactions and heterodimeric synthons generate ribbons running approximately parallel to $b c$ plane. Finally, homodimeric synthons of $\mathrm{R}_{2}^{2}(8)$ graph-set motif formed by $\mathrm{N}-\mathrm{H}^{\cdots} \mathrm{N}$ interactions between adjacent Mel molecules and $\mathrm{N}-\mathrm{H}^{\cdots} \mathrm{O}$ interactions complete the 3D packing (Fig. 1a). OPOTUK crystallizes in the triclinic space group $P-1$ with four Furas, two Mels and five water molecules of crystallization in the asymmetric unit. Each Mel molecule is engaged in the bifacial recognition of two Fura molecules forming S7 synthons. Two TPI coplanar $W C$ pairs of $\mathrm{Mel}$ and Fura molecules, linked by $\mathrm{N}-\mathrm{H} \cdots \mathrm{O}$ hydrogen bonds [graph set $\mathrm{R}_{4}^{2}(8)$ ], alternate via $A D A / D A D$ hydrogen bonds pairs of Fura molecules bonded through $\mathrm{N}-\mathrm{H} \cdots \mathrm{O}$ interactions [graph set $\mathrm{R}_{2}^{2}(8)$ ] to form ribbons along the direction of the $c$ axis. (Fig. 1b). Water molecules play a crucial role in the crystal structure of OPOTUK. They serve as hydrogen-bond donor and acceptor to connect ribbons and prevent the hydrogen-bonding interface of Mel to form a third TPI. One of the water molecules shows an approximately trigonal coordination, hydrogen bonds to one Mel and one Fura molecule $\left(\mathrm{O}_{\mathrm{w}}-\mathrm{H} \cdots \mathrm{N}\right.$, $\left.\mathrm{N}-\mathrm{H} \cdots \mathrm{O}_{\mathrm{w}}\right)$ [graph set $\mathrm{R}^{2}{ }_{3}(10)$ ], and to an adjacent water molecule $(\mathrm{Ow}-\mathrm{H} \cdots \mathrm{Ow})$. 
The five independent water molecules are arranged in channels parallel to the $a$ axis. In both structures, no relevant intermolecular XBs involving the fluorine atom were observed.

5-Chlorouracil/Melamine (2:1), CluraMel, takes the triclinic space group $P-1$. The asymmetric unit exhibits Mel molecule $W C$-paired to Clura molecule showing monofacial recognition via the S6 synthon. This $W C$-pair is then linked to a second Clura molecule through the insertion of a water molecule, which prevents Mel to be involved in bifacial recognition, so forming a tetrameric unit. In the crystal, a tetrameric unit is inserted between two inversion-symmetric tetramers, forming from one side quintuple $D A D A D$ arrays via fused rings with graph-set motif $\mathrm{R}_{3}^{3}(10), \mathrm{R}_{4}^{2}(8), \mathrm{R}_{3}^{3}(10)$ and $\mathrm{R}_{3}^{3}(10)$ based on $\mathrm{N}-\mathrm{H} \cdots \mathrm{O}, \mathrm{N}-\mathrm{H} \cdots \mathrm{O}_{\mathrm{w}}$ and $\mathrm{O}_{\mathrm{w}}-\mathrm{H} \cdots \mathrm{O}$ interactions, and from the opposite side quadruple $D A D A$ arrays via fused rings with graph set motif $\mathrm{R}_{3}^{2}(8)$, $\mathrm{R}_{2}^{2}(8)$ and $\mathrm{R}_{3}^{2}(8)$ through $\mathrm{N}-\mathrm{H} \cdots \mathrm{O}$ and $\mathrm{N}-\mathrm{H} \cdots \mathrm{N}$ interactions (Fig. 1c). These multiple arrays generate supramolecular sheets via further $\mathrm{N}-\mathrm{H} \cdots \mathrm{O}$ (homosynthon) hydrogen bonds between self-pairing centrosymmetric Clura molecules forming an $\mathrm{R}_{2}^{2}(8)$ ring motif. One of the two quadrupole $D A D A$ arrays is then reinforced by a $\mathrm{C}-\mathrm{Cl}{ }^{\cdots} \mathrm{O} \mathrm{XB}\left(2.965 \AA, 163.4^{\circ}\right)$, "lateral" to the $W C$-pair, with the remaining free imide-carbonyl acceptor site of one Clura molecule. The XB ratio $R_{\mathrm{XB}}$ equal to 0.91 .

5-Bromouracil/Melamine (2:1), BruraMel, is isomorphic and isostructural with CluraMel (Fig. 1d). For this reason, the discussion of the crystal packing of BruraMel follows the above description. The crystal structure (Fig. 1d) shows a short C-Br* $\mathrm{O}$ XB $\left(2.935 \AA, 160.6^{\circ}\right)$, and the $\mathrm{XB}$ ratio $R_{\mathrm{XB}}$ is equal to 0.87 .

5-Iodouracil/Melamine (2:1), IuraMel, crystallizes in the monoclinic space group $C 2 / c$, with one Iura molecule, half a molecule of $\mathrm{Mel}$ and one water molecule of crystallization in the 
asymmetric unit. In the crystal, a crystallographic two-fold axis passing through the N4, C8, N11 atoms of Mel generates the S8 heterotrimeric synthon utilized for bifacial recognition of two Iura molecules. Adjacent trimeric units form adjoining hydrogen-bonded rings of $\mathrm{R}_{4}^{3}(10), \mathrm{R}_{4}^{2}(12)$ and $\mathrm{R}_{4}^{3}(10)$ motifs involving $\mathrm{N}-\mathrm{H} \cdots \mathrm{O}, \mathrm{N}-\mathrm{H}^{\cdots} \mathrm{O}_{\mathrm{w}}$ and $\mathrm{O}_{\mathrm{w}}-\mathrm{H} \cdots \mathrm{O}$ interactions and form supramolecular ribbons running along the direction of the $b$ axis (Fig. 1e). As in OPOTUK, water molecules, hosted in channels parallel to the $a$ axis, are linked to Mel by $\mathrm{O}_{\mathrm{w}}-\mathrm{H} \cdots \mathrm{N}_{\text {ring }}$ interactions, and prevent the hydrogen-bonding interface of Mel to form a third TPI. Antiparallel ribbons are then connected by short $\mathrm{C}-\mathrm{I}^{\cdots} \mathrm{O}_{\mathrm{w}}\left(3.435 \AA, 154.9^{\circ}\right)$ interactions, thereby generating a two-dimensional network parallel to the $b c$ plane, and the $\mathrm{XB}$ ratio $R_{\mathrm{XB}}$ equal to 0.85 .

5-Bromo-1-methyluracil/Melamine (2:1), BrmuraMel, crystallizes in the monoclinic space group $C 2 / c$, and the asymmetric unit consists of a TPI coplanar WC pair formed by a disordered molecule of Brmura and a half Mel molecule. In the crystal, the heterotrimeric S9 synthon is generated by a crystallographic two-fold axis passing through the N5, C12, N9 atoms of Mel. Each heterotrimeric synthon is linked to adjacent heterotrimeric synthons via $\mathrm{R}_{4}^{2}(12) \mathrm{N}-\mathrm{H} \cdots \mathrm{O}$ hydrogen bonds (Fig. 1f), leading to a one-dimensional hydrogen-bonded network running along the $b$ axis. This arrangement is then reinforced by a short "lateral" $\mathrm{C}-\mathrm{Br}{ }^{\cdots} \mathrm{O}\left(2.855 \AA, 159.8^{\circ}\right)$ interaction, and the $\mathrm{XB}$ ratio $R_{\mathrm{XB}}$ equal to 0.85 . 


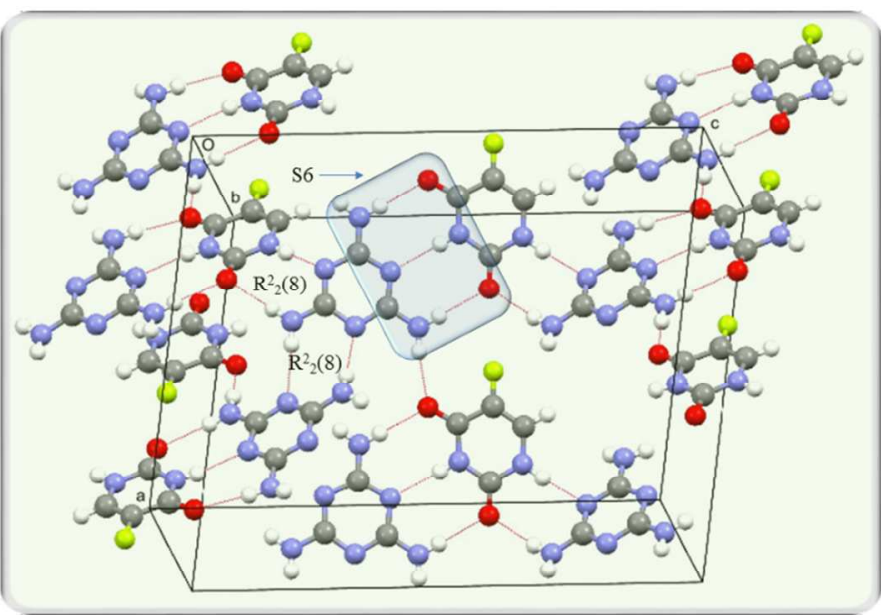

1a

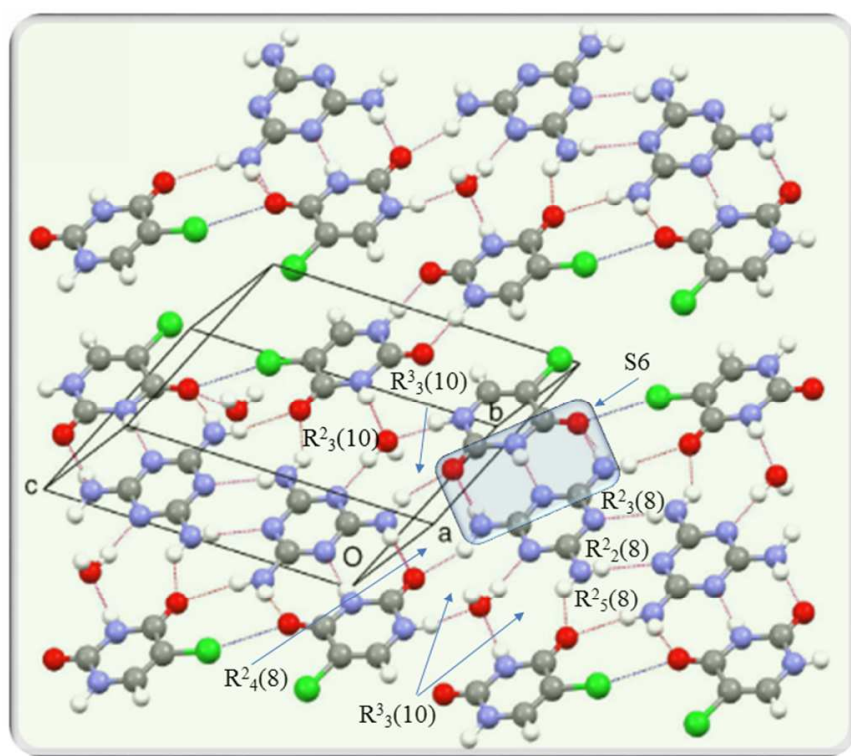

$1 \mathrm{c}$

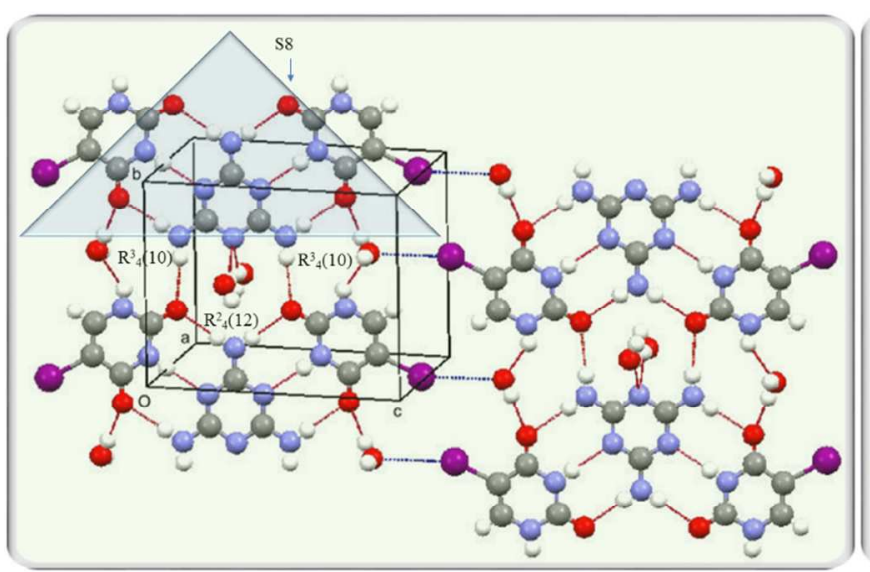

1e

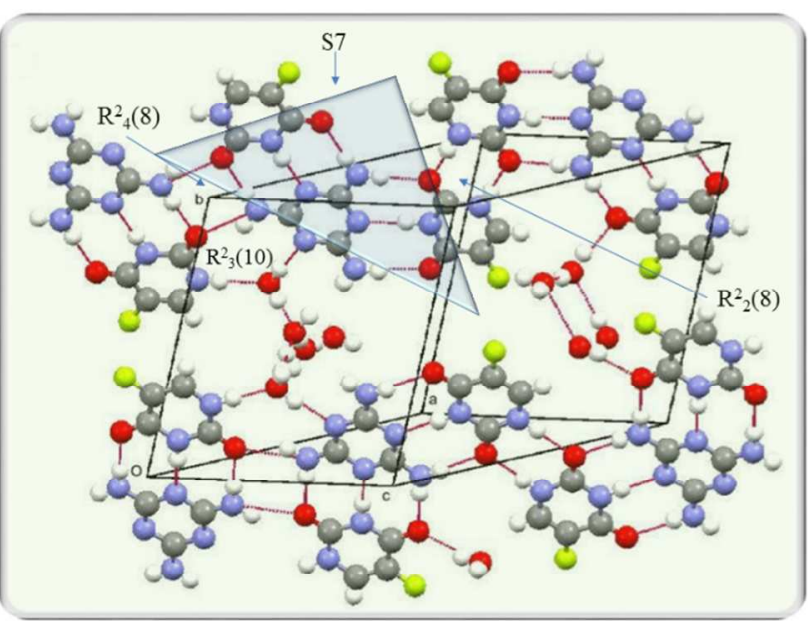

$1 \mathrm{~b}$

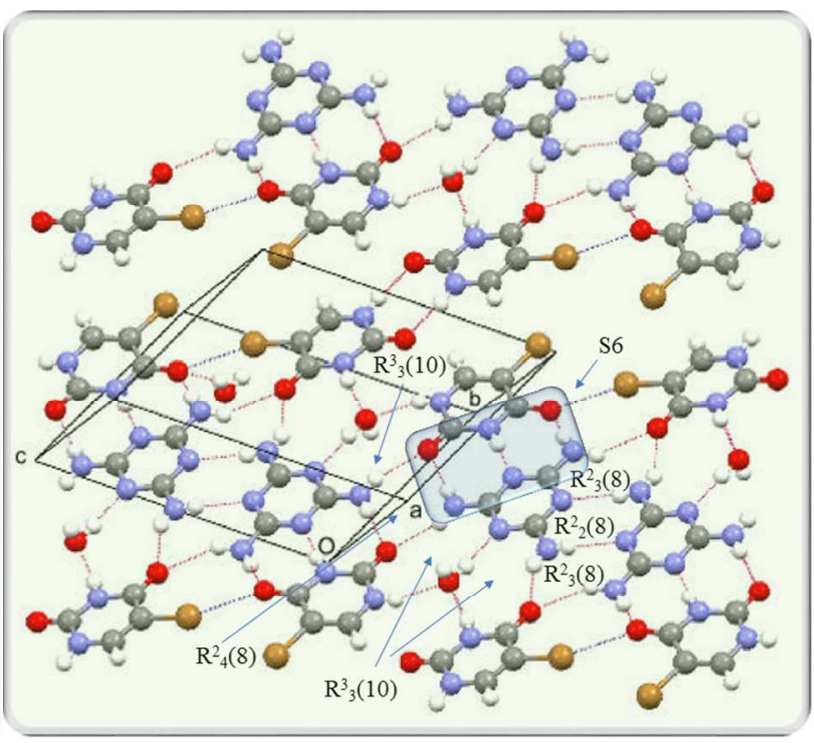

$1 \mathrm{~d}$

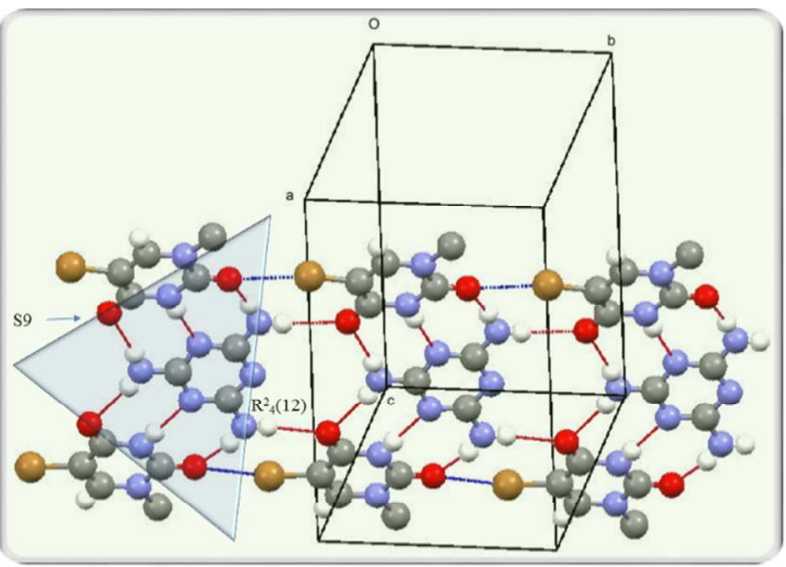

If 
Figure 1. Molecular aggregations formed in OPOVAS (1a), OPOTUK (1b), CluraMel (1c), BruraMel (1d), IuraMel (1e) and BrmuraMel (1f). For the sake of clarity, in (1f) only the majoroccupied sites of the disordered Brmura molecule are shown. Hydrogen bonds are shown as red dotted lines. Halogen bonds are shown as blue dotted lines.

\section{A-B cocrystals with $2,4,6$-Triaminopyrimidine (Tap) as coformer B}

5-Chlorouracil/2,4,6-Triaminopyrimidine (1:1), CluraTap, crystallizes in the monoclinic space group $P 2{ }_{1} / n$. The asymmetric unit contains a TPI coplanar reversed $W C$-pair of Clura molecule forming the S10 synthon. A $N, N$-dimethylformamide (DMF) solvent molecule is linked to Tap by $\mathrm{N}-\mathrm{H} \cdots \mathrm{O}$ hydrogen bonds and prevents Tap to be involved in bifacial recognition. In the crystal, these heterotrimeric units are interconnected through $\mathrm{R}_{2}^{2}(8) \mathrm{N}-\mathrm{H} \cdots \mathrm{O} / \mathrm{N}-\mathrm{H} \cdots \mathrm{N}$ and $\mathrm{R}^{2}{ }_{4}(12) \mathrm{N}-\mathrm{H} \cdots \mathrm{O}$ hydrogen bonds, generating a two-dimensional network on the $a c$ plane (Fig. 2a). No relevant intermolecular XBs involving the chlorine atom were observed.

5-Bromouracil/2,4,6-Triaminopyrimidine (2:1), BruraTap, crystallizes in the monoclinic space group $P 2{ }_{1} / n$. In the asymmetric unit, a Tap molecule showing bifacial recognition is protonated at an imino atom and inserted between a Brura molecule deprotonated at the N3 position and a neutral Brura molecule, so forming two reversed WC-pairs via charged and uncharged TPI (S11 synthon). The asymmetric unit is then completed by one $N, N$-dimethylformamide (DMF) solvent molecule and one water molecule linked to the heterotrimeric synthon through $\mathrm{N}-\mathrm{H} \cdots \mathrm{O}$ hydrogen bonds. In the crystal, heterotrimeric S11 synthons alternate with centrosymmetric synthons through $\mathrm{R}_{2}^{2}(8) \mathrm{N}-\mathrm{H} \cdots \mathrm{O}$ HB to form zigzag chains running along the $a$ axis (Fig. 2b). 
Water molecules act as a bridge between lateral sides of parallel chains via $\mathrm{N}-\mathrm{H} \cdots \mathrm{O}_{\mathrm{w}}$ and weak

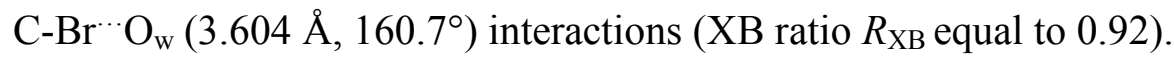

5-Iodouracil/2,4,6-Triaminopyrimidine (2:1), IuraTap, crystallizes in the monoclinic space group $C 2 / c$. The asymmetric unit contains one Iura molecule sharing a hydrogen atom with a half Tap molecule via charged TPI, and one water molecule of crystallization. Bifacial recognition is obtained through the formation of the heterotrimeric S12 synthons, which are generated by a crystallographic two-fold axis passing through the N4, C8, N11 atoms of Mel. The molecular aggregation is similar to that of IuraMel (Fig. 2c). Adjacent trimeric synthons are interlinked by $\mathrm{R}_{4}^{3}(10), \mathrm{R}_{4}^{2}(12)$ and $\mathrm{R}_{4}^{3}(10)$ motifs involving $\mathrm{N}-\mathrm{H} \cdots \mathrm{O}, \mathrm{N}-\mathrm{H} \cdots \mathrm{O}_{\mathrm{w}}$ and $\mathrm{O}_{\mathrm{w}}-\mathrm{H} \cdots \mathrm{O}$ interactions to form supramolecular ribbons running along the $b$ direction. Additional $\mathrm{O}_{\mathrm{w}}-\mathrm{H} \cdots \mathrm{O}$ hydrogen bonds link Iura to water molecules disposed in channels parallel to the $a$ axis. As in IuraMel, antiparallel ribbons are then connected by short C-I $\cdots \mathrm{O}_{\mathrm{w}}\left(3.456 \AA, 158.9^{\circ}\right)$ interactions, generating a two-dimensional network parallel to the $b c$ plane and the $\mathrm{XB}$ ratio $R_{\mathrm{XB}}$ equal to 0.85 .

5-Bromo-1-methyluracil/2,4,6-Triaminopyrimidine (2:1), BrmuraTap, crystallizes in the monoclinic space group $P 2{ }_{1} / c$, and in the asymmetric unit one Tap molecule is involved in bifacial recognition. Each Tap molecule, protonated at an imino atom, is inserted between a disordered neutral Brmura molecule and a disordered Brura molecule deprotonated at the N3 position, to form the S13 heterotrimeric synthon. In the crystal, adjacent trimeric synthons are connected by $\mathrm{N}-\mathrm{H} \cdots \mathrm{O}$ hydrogen bonds, leading to a one-dimensional network running along the $c$ axis (Fig. 2d). Depending on the orientation of the disordered neutral Brmura molecule, this arrangement is reinforced by a short "lateral" $\mathrm{C}-\mathrm{Br}{ }^{\cdots} \mathrm{O}\left(2.821 \AA, 138.4^{\circ}\right)$ interaction, and the XB ratio $R_{\mathrm{XB}}$ equal to 0.84 . 

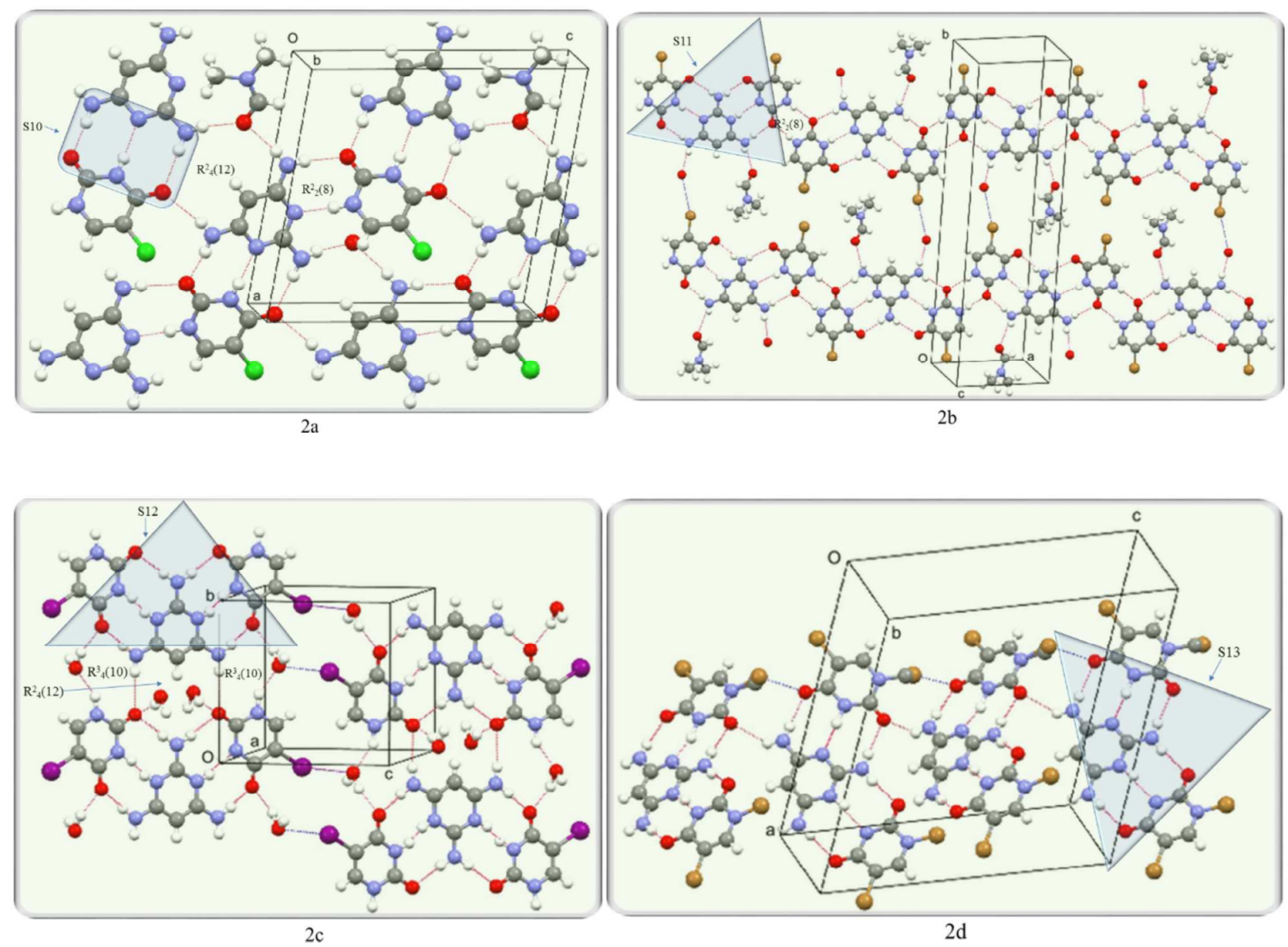

Figure 2. Molecular aggregations formed in CluraTap (2a), BruraTap (2b), IuraTap (2c) and BrmuraTap (2d). For the sake of clarity, only the major-occupied sites of the disordered Iura molecule are shown in (2c). Both disordered Brura components are shown in (2d). Hydrogen bonds are shown as red dotted lines. Halogen bonds are shown as blue dotted lines.

\section{A-B cocrystals with 2,6-diaminopyridine (Dap) as coformer B}

5-Fluorouracil/2,6-Diaminopyridine (3:1), FuraDap, which crystallizes in the triclinic space group $P-1$, contains five different entities in the asymmetric unit to form a pentameric unit. One Dap cation, linked to one DMF and to two neutral Fura molecules forming $\mathrm{R}_{2}^{2}(8)$ interactions, is 
$W C$-paired via charged TPI to one Fura anion (S14 synthon). In the crystal, a supramolecular one-dimensional array is formed by the self-assembly of pentameric synthons via fused rings [graph set notation $\mathrm{R}_{4}^{3}(12), \mathrm{R}_{2}^{2}(8)$, and $\mathrm{R}_{2}^{2}(8)$ ] through $\mathrm{N}-\mathrm{H} \cdots \mathrm{O}$ interactions. (Fig. 3a). As with OPOVAS and OPOTUK structures, no relevant intermolecular XBs involving the fluorine atom were observed.

5-Bromouracil/2,6-Diaminopyridine (1:1), BruraDap, crystallizes in the monoclinic space group $P 2{ }_{1} / c$. The asymmetric unit contains a Dap molecule protonated at imino $\mathrm{N}$ atom and a Brura molecule deprotonated at the N3 position, linked to form the S14 synthon. In the crystal, tetrameric units are formed by centrosymmetric heterodimers linked via $\mathrm{R}^{2}{ }_{2}(8) \mathrm{N}-\mathrm{H} \cdots \mathrm{O}$ hydrogen bonds. These tetrameric units are then connected to neighboring molecular adducts through $\mathrm{N}-\mathrm{H} \cdots \mathrm{O}$ hydrogen bonds (Fig. 3b). At variance with BrmuraMel and BrmuraTap, no relevant intermolecular XBs involving the bromine atom were observed.

5-Iodouracil/2,6-Diaminopyridine (2:1), IuraDap, crystallizes in the triclinic space group $P-1$. The asymmetric unit includes a heterotetrameric unit. A Dap molecule protonated at the imino N atom forms the S14 synthon with one Iura molecule deprotonated at the N3 position. The dimer is then linked to a second neutral iura molecule and to one $N, N$-dimethylformamide (DMF) solvent molecule through $\mathrm{N}-\mathrm{H} \cdots \mathrm{O}$ hydrogen bonds. In the crystal, heterotetrameric units are connected in chains to symmetry-related neighbors through $\mathrm{N}-\mathrm{H} \cdots \mathrm{O}$ hydrogen bonds between neutral Iura molecules forming an $\mathrm{R}_{2}^{2}(8)$ heterodimeric synthon (Fig. 3c). These units are further connected by $\mathrm{N}-\mathrm{H} \cdots \mathrm{O}$ hydrogen bonds to adjacent neutral Iura molecules yielding a three-dimensional network. At variance with IuraMel and IuraTap structures, no intermolecular XBs involving the iodine atom were observed. 
5-Bromo-1-methyluracil/2,6-Diaminopyridine (1:1), BrmuraDap, crystallizes in the monoclinic space group $P 2{ }_{1} / c$. The asymmetric unit contains a Dap molecule, protonated at imino $\mathrm{N}$ atom, linked to a Brmura molecule, deprotonated at the N3 position, to form the S15 synthon. In the crystal, adjacent tetrameric units, formed by centrosymmetric $W C$-pairs through $\mathrm{N}-\mathrm{H} \cdots \mathrm{O}$ hydrogen bonds [graph set notation $\mathrm{R}_{4}^{2}(8)$ ], generate a one-dimensional network by additional $\mathrm{N}-\mathrm{H} \cdots \mathrm{O}$ interactions (Fig. 3d). As in BruraDap, no relevant intermolecular XBs involving the bromine atom were observed.

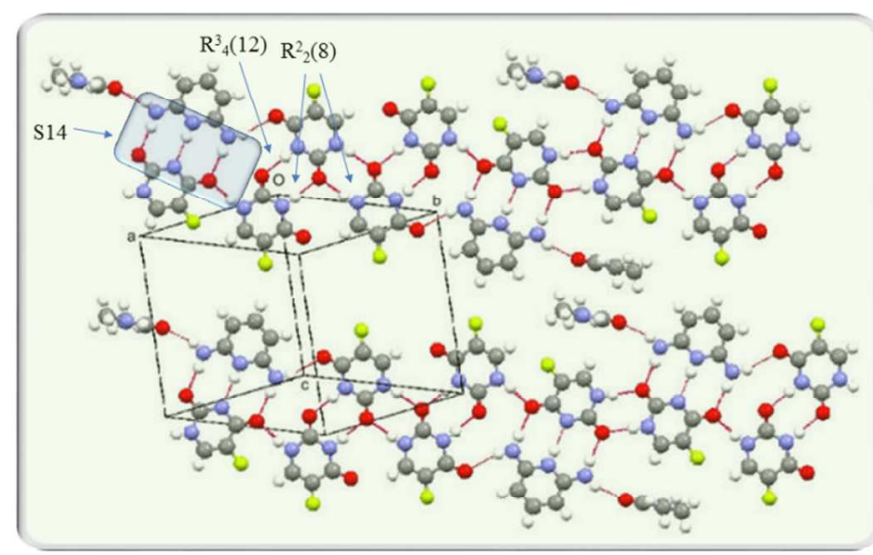

$3 a$

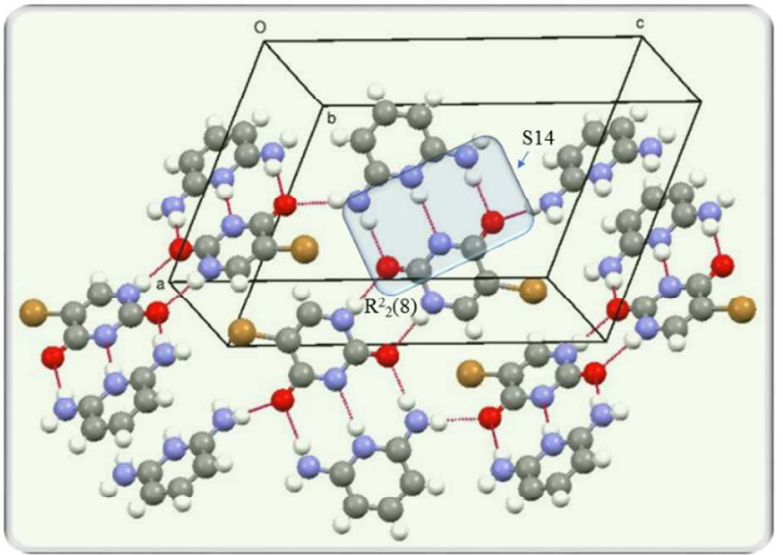

$3 b$

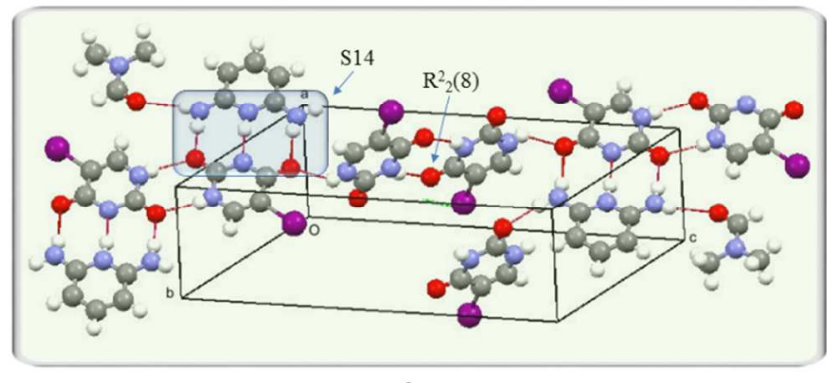

$3 \mathrm{c}$

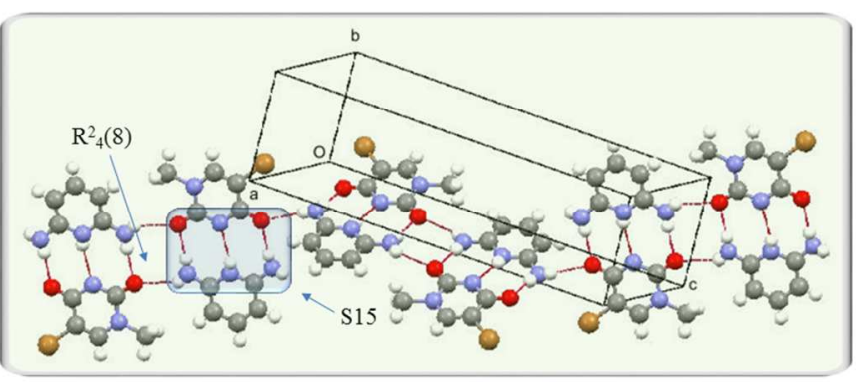

$3 d$

Figure 3. Molecular aggregations formed in FuraDap (3a), BruraDap (3b), IuraDap (3c) and BrmuraDap (3d). Hydrogen bonds are shown as red dotted lines. 


\section{A-B-A' cocrystals with 2,4,6-triaminopyrimidine (Tap) as coformer B}

5-Fluorouracil/2,4,6-Triaminopyrimidine/1-Methyluracil (1:1:1), FuraTapMura, crystallizes in the triclinic space group $P-1$. A Janus Tap molecule, one Mura molecule and one Fura molecule constitute the asymmetric unit (S16 synthon). In this triad, a protonated Tap molecule realizes bifacial recognition of two different nucleobases. From one side, a protonated Tap molecule interacts in reversed coplanar $W C$-fashion with the more acidic Fura molecule $\left(\mathrm{p} K_{\mathrm{a}}\right.$ in water $=$ 7.93), deprotonated at the $\mathrm{N} 3$ position, through ionized TPI in the $A A A / D D D$ sense. The opposite nitrogen-rich side of Tap forms a reversed coplanar $W C$-pair with the less acidic Mura molecule $\left(\mathrm{p} K_{\mathrm{a}} \text { in water }=9.77\right)^{99}$ through TPI in the traditional alternate $A D A / D A D$ sense.

In the crystal, adjacent triads are linked to form $\mathrm{R}^{2}{ }_{4}$ (12) rings based on $\mathrm{N}-\mathrm{H} \cdots \mathrm{O}$ hydrogen bonds (Fig. 4). These interactions propagate to form ribbons along the $c$ axis. These ribbons are then connected to antiparallel ribbons by further $\mathrm{N}-\mathrm{H} \cdots \mathrm{O}$ hydrogen bonds which form hydrogen-bonded rings of $\mathrm{R}_{6}^{4}(20)$ motif. No appreciable intermolecular XBs are present in the structure.

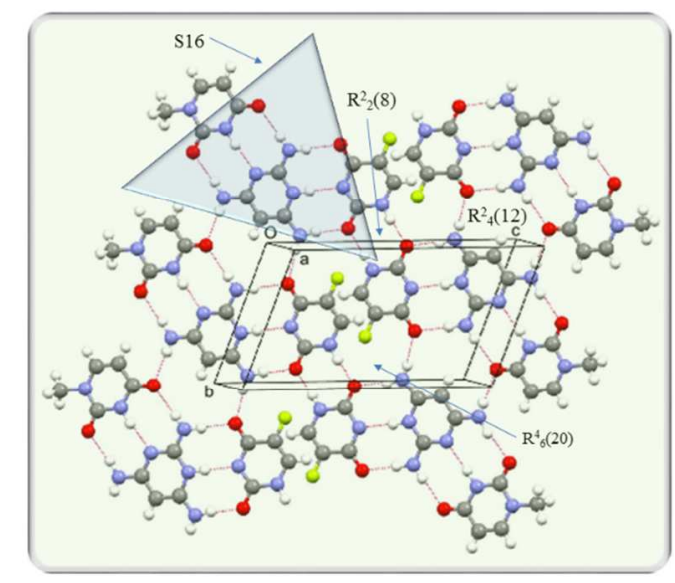

Figure 4. Molecular aggregations formed in FuraTapMura. Hydrogen bonds are shown as red dotted lines. 


\section{Crystallographic evidences of intercomponent proton transfer in cocrystals 6-13}

In the crystal structures of cocrystals 6-13, coformers B (Tap and Dap) are protonated at the $\mathrm{N} 7$ position by proton transfer from the N3 atom of coformers $\mathrm{A}$. This is evidenced by the location of the proton in difference Fourier maps (Fig. 5).

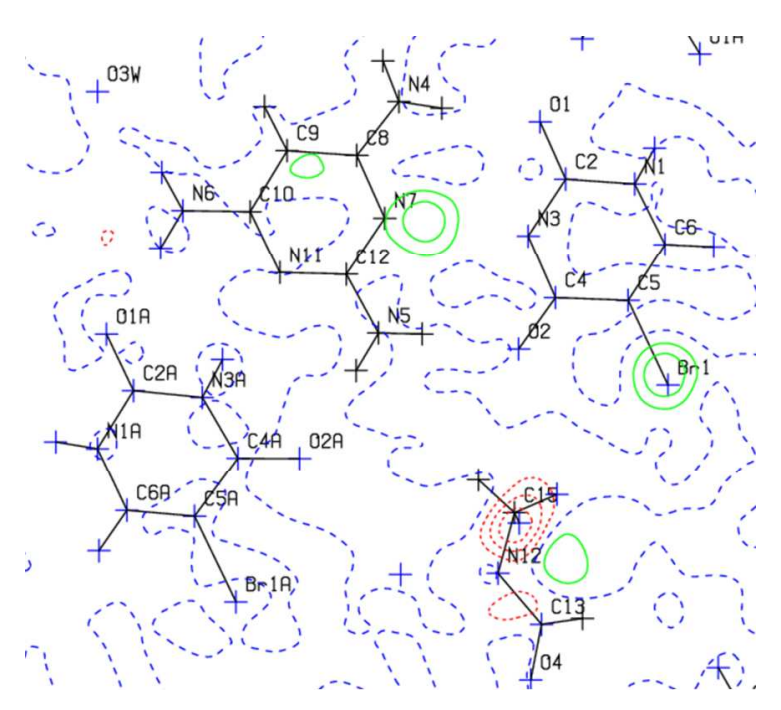

$$
5 \mathrm{a}
$$

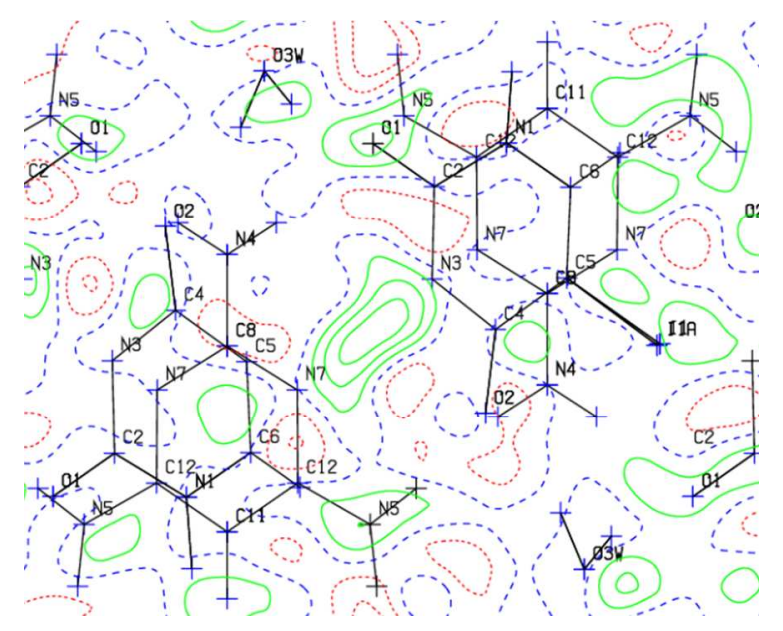

$5 b$ 


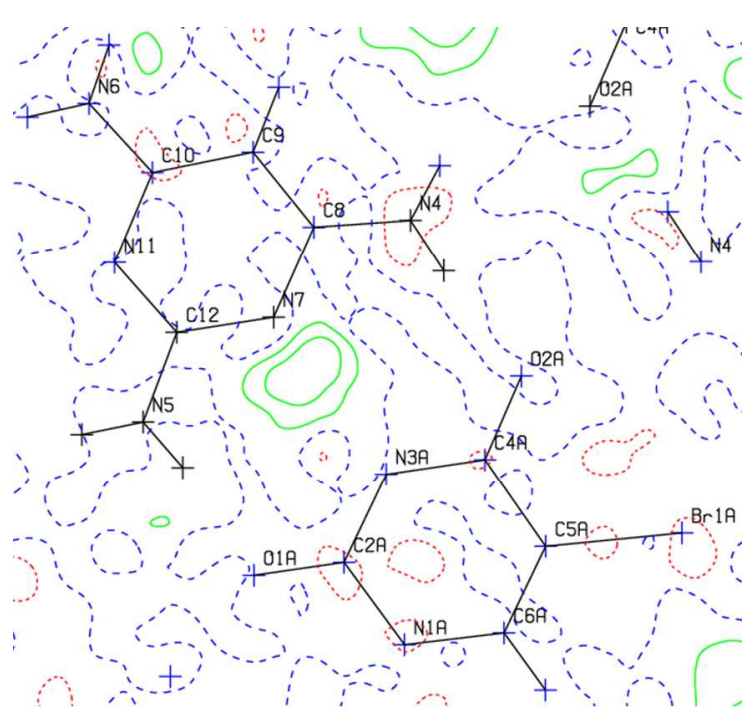

$5 c$

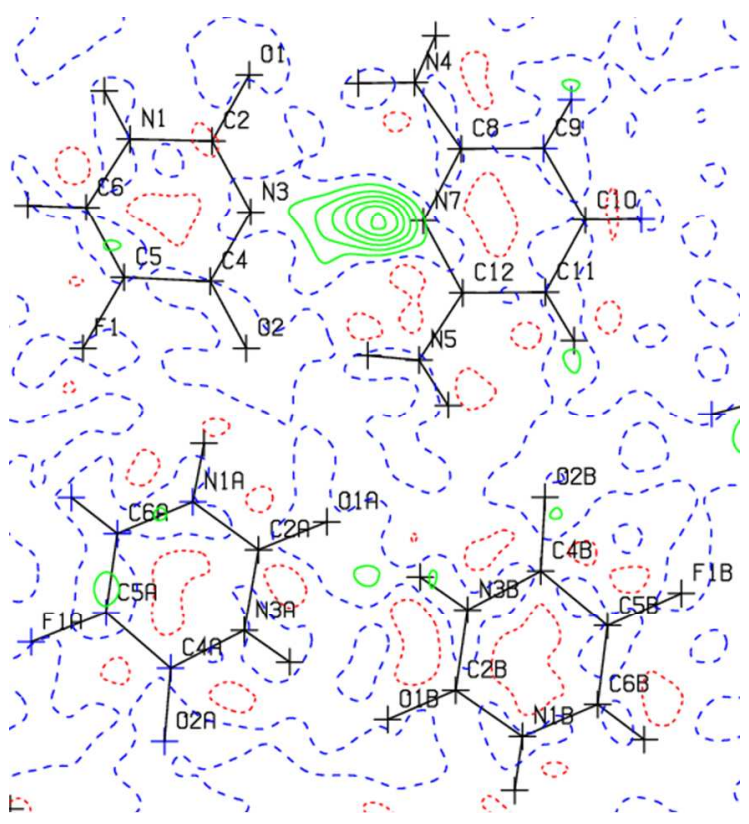

$5 d$

ACS Paragon Plus Environment 


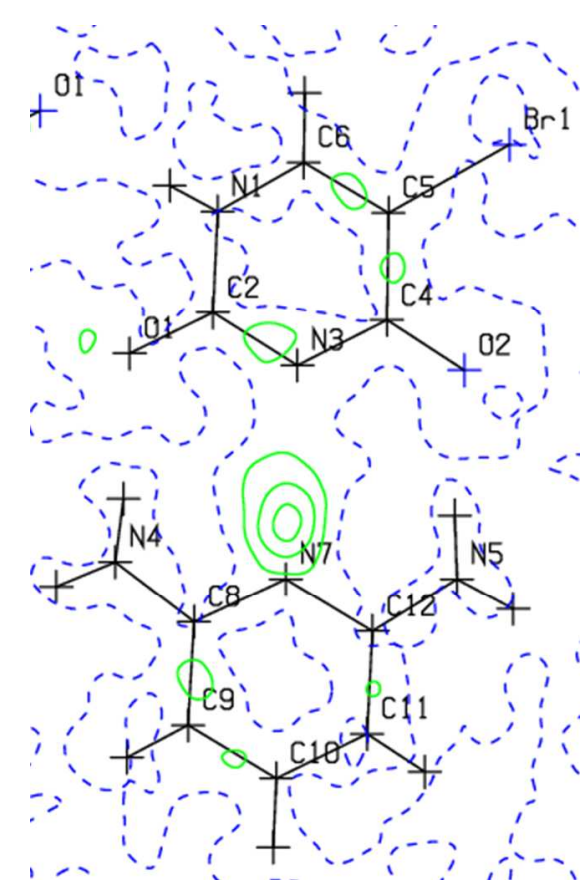

$5 \mathrm{e}$

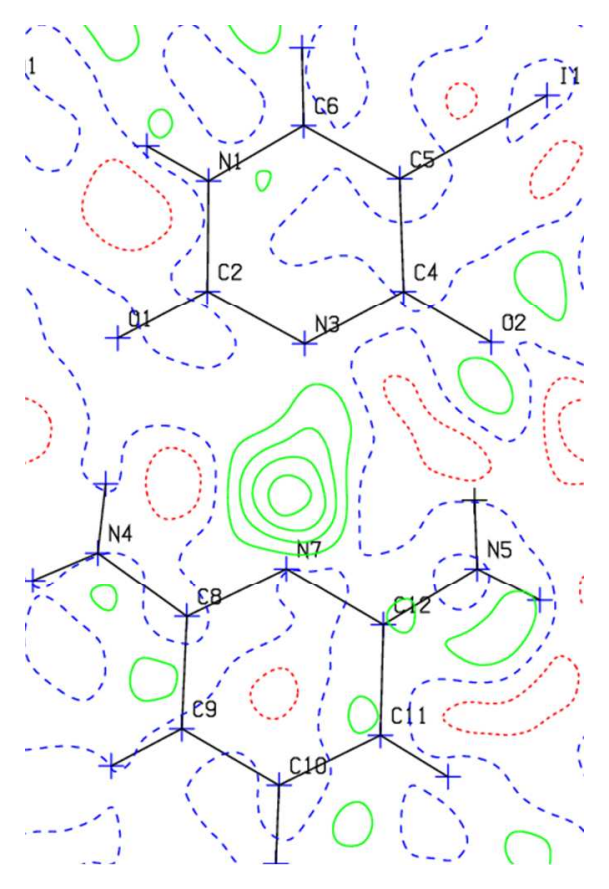

$5 f$

ACS Paragon Plus Environment 


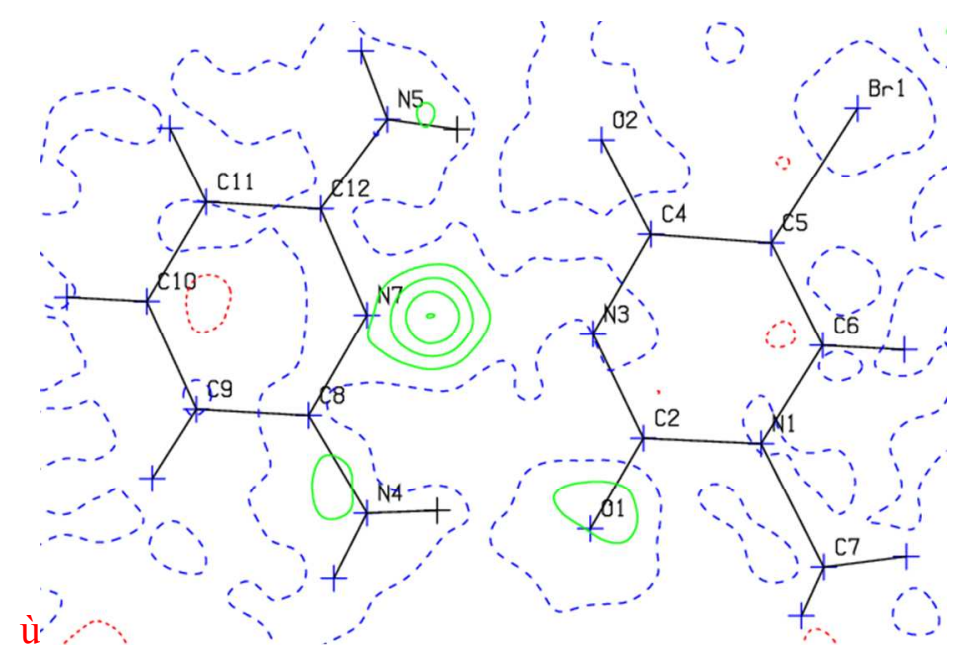

$5 g$

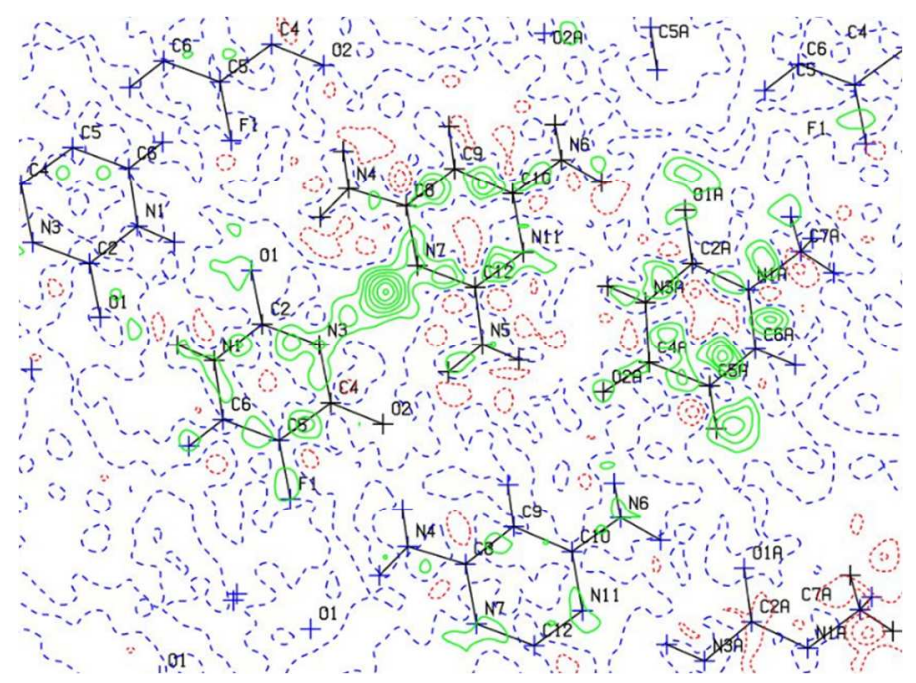

$5 \mathrm{~h}$

Figure 5. Difference Fourier map through N4, N5 and N7 of cocrystals 6 (5a), 7 (5b), 8 (5c), 9 (5d), $10(5 \mathrm{e}), 11(5 \mathrm{f}), 12(5 \mathrm{~g})$ and $13(5 \mathrm{~h})$, illustrating the hydrogen atom position within the N3 ${ }^{\cdots}$ N7 hydrogen bond. 
As regards the protonation at the $\mathrm{N} 7$ site of coformers $\mathrm{B}$, some general features emerge by comparing the molecular geometry of the planar N4-C8-N7-C12-N5 neutral fragment of Mel and Tap coformers in cocrystals 1-5 with the corresponding ionized fragment of Tap and Dap molecules in cocrystals 6-13. The range of values of the C8-N7 and C12-N7 bond distances in the protonated fragment is $1.348(6)-1.380(2) \AA$, slightly above the corresponding range in the non-protonated fragment, 1.339(2) - 1.361(2) $\AA$. No appreciable conjugation has been found within the fragment, as the range of $\mathrm{C} 8-\mathrm{N} 4$ and $\mathrm{C} 12-\mathrm{N} 5$ bond distances in the protonated $[1.319(6)-1.351(2) \AA]$ and non-protonated $[1.325(2)-1.358(7) \AA]$ forms are apparently equal within experimental error. More persuading evidence of the protonation at the N7 position comes from the values of the internal C8-N7-C12 bond angle, which fall in the interval 113.5(2) $115.6(1)^{\circ}$ in cocrystals exhibiting neutral Mel coformer, and differ significantly from those of similar angles, 120.3(6) $-124.1(3)^{\circ}$, in protonated Tap and Dap coformers. These differences agree with the VSEPR model, according to which the lone pair on deprotonated aza nitrogen atom requires a wider region than the covalent bond $\mathrm{N}^{+}-\mathrm{H}$, causing the internal angle on the former to be smaller than that on the protonated $\mathrm{N}$ atom.

By analogy, in coformers A proton migration from the N3 position shows opposite variations in the ring structure and the exocyclic bond lengths, and formal negative charge at the $\mathrm{N} 3$ atom is expected to increase the delocalization of electrons from the $\mathrm{N}$ atom to the adjacent $\mathrm{O} 1$ and $\mathrm{O} 2$ carbonyl atoms. Choosing as a probe the planar O1-C2-N3-C4-O2 fragment, the range of values of the $\mathrm{C}-\mathrm{N}$ bond distances of the ionized moiety, 1.339(7) - 1.368(6) $\AA$, is below the corresponding range in the same fragment of neutral coformers A, 1.363(3) - 1.388(8) $\AA$. Within the same fragment, the C-O bond distances fall in the range 1.238(6) -1.258(2) $\AA$ in the ionized moieties, significantly above the corresponding range (1.207(7) - 1.240(2) $\AA$ ) in the 
neutral moieties. Concerning the angle at N3, the increase of $4-6^{\circ}$ observed in passing from the ionized to the neutral moiety is highly significant and in agreement with the VSEPR model.

As expected, the hydrogen bonding interactions which take place between the opposite faces in A-B cocrystals are more effective in the ion-paired cocrystals, where the effect of the opposing charges is manifested in the shortening of the $\mathrm{N}-\mathrm{H}^{\cdots} \mathrm{O}$ and $\mathrm{N}-\mathrm{H}^{\cdots} \mathrm{N}$ distances. Indeed, the values of the $\mathrm{N} 4{ }^{\cdots} \mathrm{O} 1, \mathrm{~N} 5{ }^{\cdots} \mathrm{O} 2$ and $\mathrm{N} 3{ }^{\cdots} \mathrm{N} 7$ hydrogen bond distances, which fall in the range $2.768(4)-2.872(2), 2.814(6)-2.884(5)$ and $2.845(2)-2.887(5) \AA$ in the ionized $(A A A / D D D)$ TPI, are significantly shorter than the corresponding distances in the neutral $(A D A / D A D)$ TPI by $0.096(3)-0.097(4), 0.0147(6)-0.2180(5)$ and 0.044(2) - 0.071(5) $\AA$, respectively. 


\section{Conclusion}

The structural analysis reveals that at least one neutral or ionized TPI heterosynthon is maintained in all the cocrystals examined and is the primary synthon in all crystal structures examined, thus confirming the robustness of the triple hydrogen-bond interaction for facial recognition. In the seven cocrystals forming neutral TPI, five show mono and bifacial recognition as the presence of solvent molecules of crystallization prevents the hydrogenbonding interface of aminoazines to be completely closed by competing with hydrogen-bonding groups to the formation of TPI. The ionized acid-base interactions reinforce $W C$-pairing in the remaining seven binary cocrystals containing Tap or Dap as coformer B, and the melamine recognition unit results to be insufficiently basic to accept a proton. In these cocrystals, at variance with all the previously reported structures of complexes containing ionized halouracils, the proton transfer reaction takes always place between the more acidic site of the 5halonucleobases (N3 atom) and the more basic $\mathrm{N}_{\text {ring }}$ atom of Tap or Dap. Consequently, proton transfer reaction favors bifacial recognition of nucleobase in the binary cocrystals in which multiple recognition is possible.

Hydrogen bonds may be considered the partially activated precursors to proton-transfer reactions. ${ }^{100}$ Although proton transfer occurring from acid to base can be qualitatively evaluated from looking at the $\Delta \mathrm{p} K_{\mathrm{a}}=\left[\mathrm{p} K_{\mathrm{a}}\right.$ (conjugate acid of the base) $-\mathrm{p} K_{\mathrm{a}}$ (acid) ${ }^{101}$ the $\mathrm{p} K_{\mathrm{a}}$ value of a molecule refers to a molecule in a water solution, and the environment of the molecules in the crystal structure may not be comparable. Nevertheless, $\Delta \mathrm{p} K_{\mathrm{a}}$ can be a useful guideline for selecting the more effective for hydrogen bonding among competing coformers in the design of cocrystals of nucleobases. ${ }^{53,102,103}$ Here, ionized acid-base $W C$-pairs are observed for $\Delta \mathrm{p} K_{\mathrm{a}}>\sim$ 1 (Dap as coformer B), and neutral $W C$-pairs are observed for $\Delta \mathrm{p} K_{\mathrm{a}}<\sim-3$ (Mel as coformer B). 
In the domain of $\Delta \mathrm{p} K_{\mathrm{a}}$ between $\sim-1$ and $\sim-3$, i. e. when Tap is coformer B, proton transfer may (BruraTap, IuraTap and BrmuraTap) or may not occur (CluraTap).

The neutral complexes formed by melamine with 5-halouracils show variable stoichiometry $(1: 1$ or $1: 2)$ with the pyrimidine nucleobase, and do not form three-fold symmetric adducts neither show 1:3 stoichiometry. Thus, the bulky substituents in the 1 or 1-5 positions do not influence the stoichiometry of the complexes and do not prevent coformers A from using all the carbonyl acceptor sites available for hydrogen and halogen bonding.

Of the fifteen crystal structures examined, halogen bonding is present only in the seven cocrystals containing molecular complexes of Mel or Tap with 5-chloro, 5-bromo or 5iodosubstituted uracils. In three (CluraMel, BruraMel and BrmuraTap) the carbonyl O2 atom and in one (BrmuraMel) the carbonyl O1 act as the acceptor. Consequently, steric hindrance plays no role in the choice of carbonyl atoms in halogen bond formation. The halogen bonds in the seven cocrystals are characterized by weak interaction strength, as witnessed by the observed reduction from the sum of vdW radii of the contact atoms (from $8 \%$ to $16 \%$ ). Nevertheless, although the crystal packing is primarily stabilized via $\mathrm{N}-\mathrm{H}^{\cdots} \mathrm{O}, \mathrm{N}-\mathrm{H}^{\cdots} \mathrm{N}$, and $\mathrm{N}^{+}-\mathrm{H}^{\cdots} \mathrm{N}^{-}$hydrogen bonds, in four complexes neighboring dimeric supermolecules are linked laterally by halogen bonds, reinforcing conventional hydrogen bonds. In pure Iura and Brura, in the absence of halogen bonding interactions, the crystal packing is dominated by conventional hydrogen bonds. ${ }^{104,105}$

A nearly linear $\mathrm{X}^{\cdots} \mathrm{O}=\mathrm{C}$ disposition has been found in MIUDAP10, ZUDTAV and ZUDTAV01, as well as in the crystal structures of 5-bromo- $N, N$-1,3-dimethyluracil, 5-iodo- $N, N$ 1,3-dimethyluracil and of their mixed (1:1) cocrystal. ${ }^{38}$ In CluraMel, BruraMel, BrmuraMel and BrmuraTap, showing weak "lateral" halogen interaction $\left(R_{\mathrm{XB}}=0.84 \div 0.92\right)$, the $\mathrm{X} \cdots \mathrm{O}=\mathrm{C}$ angles 
are $158.1(1)^{\circ}, 154.5(1)^{\circ}, 160.1(1)^{\circ}$ and $144.0(2)^{\circ}$, respectively. These values exemplify significant deviations from the value commonly found for this angle, close to $120^{\circ} .{ }^{106,107}$ The examples above could suggest that strong $\mathrm{XB}$ with carbonyl oxygen atoms favors a $\mathrm{X} \cdots \mathrm{O}=\mathrm{C}$ angle of $120^{\circ}$, corresponding to the alignment with the $s p^{2}$ orbitals on carbonyl oxygen atoms. In the presence of weak XB, this angle becomes more sensitive to additional interactions present in the structure.

The first ternary A-B-A' cocrystal, FuraTapMura, has been realized in which two target nucleobases (A, Fura and A', Mura), differing in acidity by $\sim 2 \mathrm{p} K_{\mathrm{a}}$ units, link a third basic probe (B, Tap) capable of bifacial recognition via TPI for the $W C$ faces of the two $\mathrm{A}, \mathrm{A}^{\prime}$ target molecules. In this triad, the Janus Tap unit forms from one side (B-A) a reversed WC base-pair through proton-transfer reaction from the more acidic site of 5-fluorouracil (coformer A) to the more basic site of TAP, which favors the DDD recognition face synthetically complementary to the AAA face of 5-fluorouracil. Tap molecule then uses the opposite side to form a neutral reversed $W C$ base-pair (B-A') through the DAD recognition face inherently complementary to the ADA face of the less acidic 1-methyluracil (coformer A'). Insertion of Tap into the two nucleobases should provide higher affinity and specificity, due to the increasing of the number of hydrogen bonds with respect to the canonical WC pairing, and to the simultaneous presence of neutral and ionized TPI hydrogen bonds. 
Table 1. Crystal Data of binary cocrystals 1-4

\begin{tabular}{|c|c|c|c|c|}
\hline & 1, CluraMel & 2, BruraMel & 3, IuraMel & 4, BrmuraMel \\
\hline Emp. Form. & $2\left(\mathrm{C}_{4} \mathrm{H}_{3} \mathrm{ClN}_{2} \mathrm{O}_{2}\right) \cdot \mathrm{C}_{3} \mathrm{H}_{6} \mathrm{~N}_{6} \cdot \mathrm{H}_{2} \mathrm{O}$ & $2\left(\mathrm{C}_{4} \mathrm{H}_{3} \mathrm{BrN}_{2} \mathrm{O}_{2}\right) \cdot \mathrm{C}_{3} \mathrm{H}_{6} \mathrm{~N}_{6} \cdot \mathrm{H}_{2} \mathrm{O}$ & $2\left(\mathrm{C}_{4} \mathrm{H}_{3} \mathrm{IN}_{2} \mathrm{O}_{2}\right) \cdot \mathrm{C}_{3} \mathrm{H}_{6} \mathrm{~N}_{6} \cdot 2\left(\mathrm{H}_{2} \mathrm{O}\right)$ & $2\left(\mathrm{C}_{5} \mathrm{H}_{2} \mathrm{BrN}_{2} \mathrm{O}_{2}\right) \cdot \mathrm{C}_{3} \mathrm{H}_{6} \mathrm{~N}_{6}$ \\
\hline$M_{\mathrm{r}}$ & 437.22 & 526.14 & 638.14 & 530.13 \\
\hline $\begin{array}{l}\text { Cryst. syst. } \\
\text { s. g. }\end{array}$ & $\begin{array}{l}\text { Triclinic } \\
P-1\end{array}$ & $\begin{array}{l}\text { Triclinic } \\
P-1\end{array}$ & $\begin{array}{l}\text { Monoclinic } \\
C 2 / c\end{array}$ & $\begin{array}{l}\text { Monoclinic } \\
C 2 / c\end{array}$ \\
\hline$a, b, c(\AA)$ & $\begin{array}{l}9.3297(5), 10.5008(7), 10.9691 \\
(7)\end{array}$ & $9.4624(7), 10.5340(8), 10.9591(9)$ & $\begin{array}{l}19.902(2), 8.6519(5), 13.5924 \\
(14)\end{array}$ & $15.9600(18), 8.6006(8), 13.6776(16)$ \\
\hline$\alpha, \beta, \gamma\left(^{\circ}\right)$ & $\begin{array}{l}113.305(6), 94.775(5), 114.103 \\
(6)\end{array}$ & $113.132(7), 94.764(6), 113.787(7)$ & $90,122.895(15), 90$ & $90,96.371(12), 90$ \\
\hline$V\left(\AA^{3}\right)$ & $861.64(12)$ & $880.54(14)$ & $1965.2(4)$ & $1865.9(4)$ \\
\hline$Z$ & 2 & 2 & 4 & 4 \\
\hline$\mu\left(\mathrm{mm}^{-1}\right)$ & 0.43 & 4.66 & 3.25 & 4.39 \\
\hline \multicolumn{5}{|c|}{ Data collection } \\
\hline $\begin{array}{l}T_{\min }, \\
T_{\max }\end{array}$ & $\begin{array}{c}0.847 \\
1.000\end{array}$ & $\begin{array}{c}0.574 \\
1.000\end{array}$ & $\begin{array}{c}0.331 \\
1.000\end{array}$ & $\begin{array}{c}0.540 \\
1.000\end{array}$ \\
\hline $\begin{array}{l}\text { Meas., } \\
\text { indep., } \\
\text { obs. refs. }\end{array}$ & $\begin{array}{l}29003 \\
5481 \\
4329\end{array}$ & $\begin{array}{c}19240 \\
5584 \\
4108\end{array}$ & $\begin{array}{c}32998 \\
3134 \\
2719\end{array}$ & $\begin{array}{l}16366 \\
2241 \\
1895\end{array}$ \\
\hline$R_{\text {int }}$ & 0.040 & 0.050 & 0.044 & 0.052 \\
\hline $\begin{array}{l}(\sin \theta / \lambda)_{\max } \\
\left(\AA^{-1}\right)\end{array}$ & 0.725 & 0.725 & 0.725 & 0.660 \\
\hline \multicolumn{5}{|l|}{ Refinement } \\
\hline $\begin{array}{l}R_{1} \\
w R_{2} \\
S\end{array}$ & $\begin{array}{l}0.039 \\
0.116 \\
1.03\end{array}$ & $\begin{array}{l}0.042 \\
0.105 \\
1.02\end{array}$ & $\begin{array}{l}0.023 \\
0.054 \\
1.10\end{array}$ & $\begin{array}{l}0.050 \\
0.106 \\
1.25\end{array}$ \\
\hline N. of pars. & 301 & 301 & 161 & 144 \\
\hline$\Delta \rho_{\max }, \Delta \rho_{\min }$ & $0.40,-0.30$ & $1.06,-0.55$ & $0.41,-0.66$ & $0.49,-0.33$ \\
\hline
\end{tabular}


2

3

4

5

6

7

8

9

10

11

12

13

14

15

16

17

18

19

20

21

22

23

24

25

26

27

28

29

30

31

32

33

34

35

36

37

38

39

40

41

42

43

44

45

46

47

48

49

50

51

52

53

54

55

56

57

58

59

60

Table 2. Crystal Data of binary cocrystals 5-8

\begin{tabular}{|c|c|c|c|c|}
\hline & 5, CluraTap & 6, BruraTap & 7, IuraTap & 8, BrmuraTap \\
\hline $\begin{array}{l}\text { Emp. } \\
\text { form. }\end{array}$ & $\mathrm{C}_{4} \mathrm{H}_{3} \mathrm{ClN}_{2} \mathrm{O}_{2} \cdot \mathrm{C}_{4} \mathrm{H}_{7} \mathrm{~N}_{5} \cdot \mathrm{C}_{3} \mathrm{H}_{7} \mathrm{NO}$ & $\mathrm{C}_{4} \mathrm{H}_{2} \mathrm{BrN}_{2} \mathrm{O}_{2} \cdot \mathrm{C}_{4} \mathrm{H}_{3} \mathrm{BrN}_{2} \mathrm{O}_{2} \cdot \mathrm{C}_{4} \mathrm{H}_{8} \mathrm{~N}_{5} \cdot \mathrm{C}_{3} \mathrm{H}_{7} \mathrm{NO} \cdot \mathrm{O}$ & $2\left(\mathrm{C}_{4} \mathrm{H}_{2.50} \mathrm{IN}_{2} \mathrm{O}_{2}\right) \cdot \mathrm{C}_{4} \mathrm{H}_{8} \mathrm{~N}_{5} \cdot 2\left(\mathrm{H}_{2} \mathrm{O}\right)$ & $\mathrm{C}_{5} \mathrm{H}_{2} \mathrm{BrN}_{2} \mathrm{O}_{2} \cdot \mathrm{C}_{4} \mathrm{HBrN}_{2} \mathrm{O}_{2} \cdot \mathrm{C}_{4} \mathrm{H}_{8} \mathrm{~N}_{5}$ \\
\hline$M_{\mathrm{r}}$ & 344.77 & 596.23 & 637.14 & 517.13 \\
\hline $\begin{array}{l}\text { Cryst. } \\
\text { syst. }\end{array}$ & Monoclinic & Monoclinic & Monoclinic & Monoclinic \\
\hline s. g. & $P 2_{1} / n$ & $P 2_{1} / n$ & $C 2 / c$ & $P 2_{1} / c$ \\
\hline $\begin{array}{l}a, b, c \\
(\AA)\end{array}$ & $\begin{array}{l}11.8918(9), 10.4962(11) \\
12.8427(9)\end{array}$ & $8.9251(11), 28.028(2), 9.7122(16)$ & $\begin{array}{l}24.695(3), 8.7205(9), 9.5372 \\
(10)\end{array}$ & $\begin{array}{l}16.5900(18), 7.0442(6) \\
16.3854(17)\end{array}$ \\
\hline $\begin{array}{l}\alpha, \beta, \gamma \\
\left({ }^{\circ}\right)\end{array}$ & $90,99.938(7), 90$ & $90,105.507$ (15), 90 & $90,101.336(11), 90$ & $90,100.424(10), 90$ \\
\hline$V\left(\AA^{3}\right)$ & $1579.0(2)$ & $2341.1(5)$ & $2013.8(4)$ & $1883.2(3)$ \\
\hline$Z$ & 4 & 4 & 4 & 4 \\
\hline $\begin{array}{l}\mu \\
\left(\mathrm{mm}^{-1}\right)\end{array}$ & 0.27 & 3.52 & 3.17 & 4.35 \\
\hline \multicolumn{5}{|c|}{ Data collection } \\
\hline $\begin{array}{l}T_{\min }, \\
T_{\max }\end{array}$ & $\begin{array}{c}0.699 \\
1.000\end{array}$ & $\begin{array}{c}0.726 \\
1.000\end{array}$ & $\begin{array}{c}0.269 \\
1.000\end{array}$ & $\begin{array}{c}0.616 \\
1.000\end{array}$ \\
\hline $\begin{array}{l}\text { Meas., } \\
\text { indep., } \\
\text { obs. } \\
\text { refns. }\end{array}$ & $\begin{array}{c}35206 \\
5015 \\
3669\end{array}$ & $\begin{array}{c}25065 \\
4844 \\
2880\end{array}$ & $\begin{array}{c}24326 \\
2434 \\
2011\end{array}$ & $\begin{array}{c}24376 \\
3697 \\
3093\end{array}$ \\
\hline$R_{\text {int }}$ & 0.046 & 0.061 & 0.110 & 0.072 \\
\hline $\begin{array}{l}(\sin \\
\theta / \lambda)_{\max } \\
\left(\AA^{-1}\right)\end{array}$ & 0.725 & 0.628 & 0.660 & 0.617 \\
\hline \multicolumn{5}{|c|}{ Refinement } \\
\hline $\begin{array}{l}R_{1} \\
w R_{2} \\
S\end{array}$ & $\begin{array}{l}0.044 \\
0.122 \\
1.03\end{array}$ & $\begin{array}{l}0.083 \\
0.224 \\
1.05\end{array}$ & $\begin{array}{c}0.044 \\
0.123 \\
1.11\end{array}$ & $\begin{array}{c}0.067 \\
0.177 \\
1.13\end{array}$ \\
\hline $\begin{array}{l}\text { N. of } \\
\text { pars. }\end{array}$ & 246 & 298 & 169 & 265 \\
\hline $\begin{array}{l}\Delta \rho_{\max } \\
\Delta \rho_{\min } \\
\left(\mathrm{e} \AA^{-3}\right)\end{array}$ & $\begin{array}{l}0.28 \\
-0.30\end{array}$ & $\begin{array}{l}1.13 \\
-0.96\end{array}$ & $\begin{array}{l}1.15 \\
-1.19\end{array}$ & $\begin{array}{l}0.98 \\
-0.42\end{array}$ \\
\hline
\end{tabular}


Table 3. Crystal Data of binary cocrystals 9-12

\begin{tabular}{|c|c|c|c|c|}
\hline & 9, FuraDap & 10, BruraDap & 11, IuraDap & 12, BrmuraDap \\
\hline $\begin{array}{l}\text { Emp. } \\
\text { form. }\end{array}$ & $\mathrm{C}_{4} \mathrm{H}_{2} \mathrm{FN}_{2} \mathrm{O}_{2} \cdot 2\left(\mathrm{C}_{4} \mathrm{H}_{3} \mathrm{FN}_{2} \mathrm{O}_{2}\right) \cdot \mathrm{C}_{5} \mathrm{H}_{8} \mathrm{~N}_{3} \cdot \mathrm{C}_{3} \mathrm{H}_{6} \mathrm{NO}$ & $\mathrm{C}_{4} \mathrm{H}_{2} \mathrm{BrN}_{2} \mathrm{O}_{2} \cdot \mathrm{C}_{5} \mathrm{H}_{8} \mathrm{~N}_{3}$ & $\mathrm{C}_{4} \mathrm{H}_{2} \mathrm{IN}_{2} \mathrm{O}_{2} \cdot \mathrm{C}_{4} \mathrm{H}_{3} \mathrm{IN}_{2} \mathrm{O}_{2} \cdot \mathrm{C}_{5} \mathrm{H}_{8} \mathrm{~N}_{3} \cdot \mathrm{C}_{3} \mathrm{H}_{7} \mathrm{NO}$ & $\mathrm{C}_{5} \mathrm{H}_{4} \mathrm{BrN}_{2} \mathrm{O}_{2} \cdot \mathrm{C}_{5} \mathrm{H}_{8} \mathrm{~N}_{3}$ \\
\hline$M_{\mathrm{r}}$ & 571.48 & 300.13 & 658.20 & 314.16 \\
\hline $\begin{array}{l}\text { Cryst. } \\
\text { syst. } \\
\text { s. g. }\end{array}$ & $\begin{array}{l}\text { Triclinic } \\
P-1\end{array}$ & $\begin{array}{l}\text { Monoclinic } \\
P 2_{1} / c\end{array}$ & $\begin{array}{l}\text { Triclinic } \\
P-1\end{array}$ & $\begin{array}{l}\text { Monoclinic } \\
P 2_{1} / c\end{array}$ \\
\hline $\begin{array}{l}a, b, c \\
(\AA)\end{array}$ & $10.4374(10), 10.5556(9), 13.5933(11)$ & $\begin{array}{l}10.4503(10), 7.1957 \\
(9), 15.7838(16)\end{array}$ & $5.2878(4), 12.1407(11), 18.4965(13)$ & $\begin{array}{l}9.4010(13), 6.0669 \\
(6), 21.367(3)\end{array}$ \\
\hline $\begin{array}{l}\alpha, \beta, \gamma \\
\left({ }^{\circ}\right)\end{array}$ & 93.408 (7), $103.393(8), 117.109(9)$ & 90, $105.424(11), 90$ & $102.322(7), 94.418(6), 101.693(7)$ & $90,90.926(14), 90$ \\
\hline$V\left(\AA^{3}\right)$ & $1273.1(2)$ & $1144.1(2)$ & $1126.99(16)$ & $1218.5(3)$ \\
\hline$Z$ & 2 & 4 & 2 & 4 \\
\hline $\begin{array}{l}\mu \\
\left(\mathrm{mm}^{-1}\right)\end{array}$ & 0.13 & 3.59 & 2.84 & 3.38 \\
\hline \multicolumn{5}{|c|}{ Data collection } \\
\hline $\begin{array}{l}T_{\min }, \\
T_{\max }\end{array}$ & $\begin{array}{l}0.833 \\
1.000\end{array}$ & $\begin{array}{c}0.467 \\
1.000\end{array}$ & $\begin{array}{l}0.958 \\
1.000\end{array}$ & $\begin{array}{c}0.572 \\
1.000\end{array}$ \\
\hline $\begin{array}{l}\text { Meas., } \\
\text { indep., } \\
\text { obs. } \\
\text { reflns. }\end{array}$ & $\begin{array}{c}16624 \\
4501 \\
3188\end{array}$ & $\begin{array}{c}18543 \\
2634 \\
2063\end{array}$ & $\begin{array}{c}17375 \\
4891 \\
3260\end{array}$ & $\begin{array}{c}5703 \\
2112 \\
1748\end{array}$ \\
\hline$R_{\text {int }}$ & 0.035 & 0.048 & 0.058 & 0.034 \\
\hline $\begin{array}{l}(\sin \\
\theta / \lambda)_{\max } \\
\left(\AA^{-1}\right)\end{array}$ & 0.596 & 0.650 & 0.639 & 0.597 \\
\hline \multicolumn{5}{|c|}{ Refinement } \\
\hline $\begin{array}{l}R_{1} \\
w R_{2} \\
S\end{array}$ & $\begin{array}{l}0.065 \\
0.198 \\
1.04\end{array}$ & $\begin{array}{l}0.037 \\
0.096 \\
1.03\end{array}$ & $\begin{array}{l}0.047 \\
0.095 \\
1.03\end{array}$ & $\begin{array}{l}0.054 \\
0.164 \\
1.08\end{array}$ \\
\hline $\begin{array}{l}\text { N. of } \\
\text { pars. }\end{array}$ & 395 & 162 & 294 & 164 \\
\hline $\begin{array}{l}\Delta \rho_{\max } \\
\Delta \rho_{\min } \\
\left(\mathrm{e} \AA^{-3}\right)\end{array}$ & $\begin{array}{l}0.79 \\
-0.48\end{array}$ & $\begin{array}{l}0.74 \\
-0.65\end{array}$ & $\begin{array}{l}0.54 \\
-0.76\end{array}$ & $\begin{array}{l}1.06 \\
-0.57\end{array}$ \\
\hline
\end{tabular}


1

2

3

4

5

6

7

8

9

10

11

12

13

14

15

16

17

18

19

20

21

22

23

24

25

26

27

28

29

30

31

32

33

34

35

36

37

38

39

40

41

42

43

44

45

46

47

48

49

50

51

52

53

54

55

56

57

58

59

60
Table 4. Crystal Data of ternary cocrystal 13

Chemical formula

$M_{\mathrm{r}}$

Crystal system, s. g.

$a, b, c(\AA)$

$\alpha, \beta, \gamma\left({ }^{\circ}\right)$

$V\left(\AA^{3}\right)$

Z

$\mu\left(\mathrm{mm}^{-1}\right)$

Data collection

$T_{\min }$

$T_{\max }$

Meas.,

indep.,

obs.reflns.

$R_{\text {int }}$

$(\sin \theta / \lambda)_{\max }\left(\AA^{-1}\right)$

Refinement

$R_{I}$

$w R_{2}$

$S$

N. of pars.

$\Delta \rho_{\max }$

$\Delta \rho_{\min }\left(\mathrm{e} \AA^{-3}\right)$

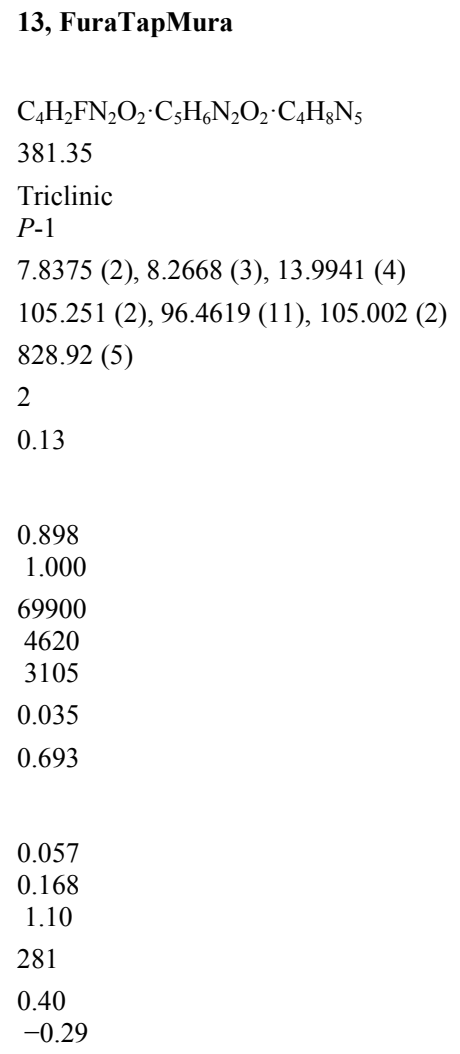




\section{ASSOCIATED CONTENT}

\section{Supporting Information}

Ortep diagrams; difference Fourier maps for cocrystals 1-5; selected geometrical parameters in Opovas, Opotuk and cocrystals 1-13; geometrical parameters of hydrogen bonds in cocrystals 113. This material is available free of charge as the ACS publication website at DOI:

\section{Accession codes}

Full crystallographic data has been deposited to the Cambridge Crystallographic Data Centre (CCDC 1839826-1839838). These data can be obtained free of charge via c.cam.uc.uk/data_request/cif, or by emailing data_request@ccdc.cam.ac.uk, or by contacting The Cambridge Crystallographic Data Centre, 12 Union Road, Cambridge CB2 1EZ, UK; fax: +44 1223336033.

\section{AUTHOR INFORMATION}

\section{Corresponding Authors}

*(G.P.) Tel.: +396 49913 106. E-mail: gustavo.portalone@uniroma1.it

*(K.R.) Tel.: +358 50562 3721. E-mail: kari.t.rissanen@jyu.fi

\section{ORCID}

Gustavo Portalone: 0000-0001-5093-1207

Kari Rissanen: 0000-0002-7282-8419 


\section{Author Contributions \\ The manuscript was written through contributions of both authors. Both authors have given approval to the final version of the manuscript.}

\section{Notes}

The authors declare no competing financial interest.

\section{Funding Sources}

The University of Jyväskylä.

\section{ACKNOWLEDGMENTS}

K.R. kindly acknowledges the special support from the Rector of the University of Jyväskylä. 


\section{References}

(1) Carell, T.; Brandmayr, C.; Hienzsch, A.; Müller, M.; Pearson, D.; Reiter, V.; Thumbs, P.; Wagner, M. Structure and Function of Noncanonical Nucleobases. Angew. Chem. Int. Ed. 2012, $51,7110-7131$.

(2) Chen, Y.; Hong, T.; Wang, S.; Mo, J.; Tian, T.; Zhou, X. Epigenetic Modification of Nucleic Acids: from Basic Studies to Medical Applications. Chem. Soc. Rev. 2017, 46, 2844-2872.

(3) Chollet, A.; Kawashima, E. DNA containing the Base Analogue 2-Aminoadenine: Preparation, Use as Hybridization Probes and Cleavage by Restriction Endonucleases. Nucl. Ac. Res. 1988, 16, 305-316.

(4) Haaima, G.; Hansen, H.F.; Christensen, L.; Dahl, O.; Nielsen, P. E. Increased DNA Binding and Sequence Discrimination of PNA Oligomers containing 2,6-Diaminopurine. Nucleic Acids Res. 1997, 25, 4639-4643.

(5) Gilbert, S. D.; Mediatore, S. J.; Matey, R. T. Modified Pyrimidines Specifically Bind the Purine Riboswitch. J. Am. Chem. Soc. 2006, 128, 14214-14216.

(6) Patra, A.; Harp, J.; Pallan, P. S.; Zhao, L.; Abramov, M.; Herdewijn, P.; Egli, M. Structure, Stability and Function of 5-Chlorouracil Modified A:U and G:U Base Pairs. Nucl. Ac. Res. 2013, $41,2689-2697$.

(7) Parker, A. J.; Stewart, J.; Donald, K. J.; Parish, C. A. Halogen Bonding in DNA Base Pairs. J. Am. Chem. Soc. 2012, 134, 5165-5172.

(8) Carter, M.; Voth, A. R.; Scholfield, M. R.; Rummel, B.; Sowers, L. C.; Ho, P. S. EnthalpyEntropy Compensation in Biomolecular Halogen Bonds Measured in DNA Junctions. Biochemistry 2013, 52, 4891-4903. 
(9) Cavallo, G.; Metrangolo, P.; Milani, R.; Pilati, T.; Priimagi, A.; Resnati, G.; Terraneo, G. The Halogen Bond. Chem. Rev. 2016, 116, 2478-2601.

(10) Rowe, R. K.; Ho, P. S. Relationships Between Hydrogen Bonds and Halogen Bonds in Biological Systems. Acta Cryst. 2017, B73, 255-264.

(11) Zimmerman, S. C.; Murray, T. J. In Computational Approaches in Supramolecular Chemistry, Wipff, G. Ed; Kluwer Academic Publishers: Dordrecht, The Netherland, 1994; pp 109-115.

(12) Benner, S.; Sismour, A. M. Synthetic Biology. Nature Rev. Genet. 2005, 6, 533-543.

(13) Shirato, W.; Chiba, J.; Inouye, M. A Firmly Hybridizable, DNA-Like Architecture with DAD/ADA- and ADD/DAA-Type Nonnatural Base Pairs as an Extracellular Genetic Candidate. Chem. Commun. 2015, 51, 7043-7046.

(14) Matsuura, M. F.; Kim, Hyn-J.; Takahashi, D.; Abboud, K. A.; Benner, S. A. Crystal Structures of Deprotonated Nucleobases from an Expanded DNA Alphabet. Acta Crystallogr., Sect. C: Cryst. Struct. Commun. 2016, 72, 952-959.

(15) Kamiya, Y.; Donoshita, Y.; Kamimoto, H.; Murayama, K.; Ariyoshi, J.; Asanuma, H. Introduction of 2,6-Diaminopurines into Serinol Nucleic Acid Improves Anti-miRNA Performance. ChemBioChem 2017, 18, 1917-1922.

(16) Etter, M. C.; MacDonald, J. C.; Bernstein, J. Graph-set Analysis of Hydrogen-Bond Patterns in Organic Crystals. Acta Crystallogr., Sect. B: Struct. Sci. 1990, 46, 256-262.

(17) Bernstein, J.; Davis, R. E.; Shimoni, L.; Chang, N.-L. Patterns in Hydrogen Bonding: Functionality and Graph Set Analysis in Crystals. Angew. Chem. Int. Ed. 1995, 34, 1555-1573. 
(18) Allen, F. H.; Motherwell, W. D. S.; Raithby, P. R. Shields, G. P.; Taylor, R. Systematic Analysis of the Probabilities of Formation of Bimolecular Hydrogen-Bonded Ring Motifs in Organic Crystal Structures. New J. Chem. 1999, 25-34.

(19) Seto, C. T.; Whitesides, G. M. Molecular Self-Assembly Through Hydrogen Bonding: Supramolecular Aggregates Based on the Cyanuric Acid-Melamine Lattice. J. Am. Chem. Soc. 1993, $115,905-916$.

(20) Ranganathan, A.; Pedireddi, V. R.; Rao, C. N. R. Hydrothermal Synthesis of Organic Channel Structures: 1:1 Hydrogen-Bonded Adducts of Melamine with Cyanuric and Trithiocyanuric Acids. J. Am. Chem. Soc. 1999, 121, 1752-1753.

(21) Prior, T. J.; Armstrong, J. A.; Benoit, D. M.; Marshall, K. L. The Structure of the Melamine-Cyanuric Acid Co-Crystal. CrystEngComm. 2013, 15, 5838-5843.

(22) Groom, C. R.; Allen, F. H. The Cambridge Structural Database in Retrospect and Prospect. Angew. Chem. Int. Ed. 2014, 53, 662-671.

(23) Sakore, T. D.; Sobell, H. M.; Mazza, F.; Gopinath Kartha G. Base-Pairing Configurations Between Purines and Pyrimidines in the Solid State: III. Crystal and Molecular Structure of two 2:1 Hydrogen-Bonded Complexes, 1-Methylthymine: 9-Ethyl-2,6-diaminopurine and 1-Methyl5-iodouracil: 9-Ethyl-2,6-diaminopurine. J. Mol. Biol. 1969, 43, 385-406.

(24) Zhou, Z.; Bong, D. Small-Molecule/Polymer Recognition Triggers Aqueous-Phase Assembly and Encapsulation. Langmuir 2013, 26, 144-150.

(25) Gerhardt, V; Egert, E. Cocrystals of 6-Chlorouracil and 6-Chloro-3-methyl-uracil: Exploring their Hydrogen-Bond-Based Synthon Motifs with Several Triazine and Pyrimidine Derivatives. Acta Crystallogr., Sect. B: Struct. Sci. 2015, 71, 209-220. 
(26) Turunen, L.; Beyeh, N. K.; Pan, F.; Valkonen, A.; Rissanen, K. Tetraiodoethynyl Resorcinarene Cavitands as Multivalent Halogen Bond Donors. Chem. Commun. 2014, 50, 15920-15923.

(27) Bondi, A. van der Waals Volumes and Radii. J. Phys. Chem. 1964, 68, 441-451.

(28) Portalone, G.; Colapietro, M.; Ramondo, F.; Bencivenni, L.; Pieretti, A. The Effect of Hydrogen Bonding on the Structures of Uracil and some Methyl Derivatives by Experiment and Theory. Acta Chem. Scand. 1999, 53, 57-68.

(29) Brunetti, B.; Piacente, V.; Portalone, G. Sublimation Enthalpies of some Methyl Derivatives of Uracil from Vapor Pressures Measurements. J. Chem. Eng. Data 2000, 45, 242-246.

(30) Brunetti, B.; Portalone, G.; Piacente, V. Sublimation Thermodynamics Parameters for 5Fluorouracil and its 1-Methyl and 1,3-Dimethyl Derivatives from Vapor Pressures Measurements. J. Chem. Eng. Data 2002, 47, 17-19.

(31) Portalone, G.; Ballirano, P.; Maras, A. The crystal structure of 3-methyluracil from X-ray powder diffraction data. J. Mol. Struct. 2002, 608, 35-39.

(32) Irrera, S.; Roldan, A.; Portalone, G.; De Leeuw. N. H. The role of hydrogen bonding and proton transfer in the formation of uracil networks on the gold (100) surface: a density functional theory approach. J. Phys. Chem. C 2013, 117, 3949-3957.

(33) Valkonen, A.; Chukhlieb, M.; Moilanen, J.; Tuononen, H.; Rissanen, K. Halogen and Hydrogen Bonded Complexes of 5-Iodouracil. Cryst. Growth Des. 2013, 13, 4769-4775.

(34) Brunetti, B.; Irrera, S.; Portalone, G. Sublimation Enthalpies of 5-Haloderivatives of 1,3Dimethyluracil. J. Chem. Eng. Data 2015, 60, 74-81. 
(35) Portalone, G.; Moilanen, J. O.; Tuononen, H. M.; Rissanen, K. Role of Weak Hydrogen Bonds and Halogen Bonds in 5-Halo-1,3-dimethyluracils and their Cocrystals - A Combined Experimental and Computational Study. Cryst. Growth Des. 2016, 16, 2631-2639.

(36) Puttreddy, R.; Topic', F.; Valkonen, A.; Rissanen, K. Halogen-Bonded Co-Crystals of Aromatic N-oxides: Polydentate Acceptors for Halogen and Hydrogen Bonds. Crystals 2017, 7, 214-225.

(37) Sowers, L. C.; Ramsay Shaw, B.; Veigl, M. L.; Sedwick, W. D. DNA base modification: Ionized base pairs and mutagenesis. Mutation Res. 1987, 177, 201-218.

(38) Mascal, M.; Fallon, P. S.; Batsanov, A. S.; Heywood, B. R.; Champ. S.; Colclough, M. The Ion-Pair Reinforced, Hydrogen-Bonding Molecular Ribbon. Chem. Commun. 1995, 805-806.

(39) Mascal, M.; Hansen, J.; Fallon, P. S.; Blake, A. J.; Heywood, B. R.; Moore, M. H.; Turkenburg, J. P. From Molecular Ribbons to a Molecular Fabric Chem. Eur. J. 1999, 5, 381385.

(40) Gratzner, H. G. Monoclonal Antibody to 5-bromo- and 5-iododeoxyuridine: A New Reagent for Detection of DNA Replication. Science 1982, 218, 474-475.

(41) Wang, C.-R.; Lu, Q.-B. Molecular Mechanism of the DNA Sequence Selectivity of 5-Halo2'-Deoxyuridines as Potential Radiosensitizers. J. Am. Chem. Soc. 2010, 132, 14710-14713.

(42) Morgan, M. T.; Bennett, M. T.; Drohat, A. C. Excision of 5-Halogenated Uracils by Human Thymine DNA Glycosylase. Robust Activity for Dna Contexts other than Cpg. J. Biol. Chem. 2007, 282, 27578-27597. 
(43) Sobolewski, I.; Polska, K.; Zylicz-Stachula, A.; Jezewska-Frackowiak, J.; Rak, J.; Skowron, P. Enzymatic Synthesis of Long Double-Stranded DNA Labeled with Haloderivatives of Nucleobases in a Precisely Pre-Determined Sequence. BMC Biochemistry 2011, 12, 47.

(44) Mondal, S.; Manna, D.; Mugesh, H. Selenium-Mediated Dehalogenation of Halogenated Nucleosides and its Relevance to the DNA Repair Pathway. Angew. Chem. Int. Ed. 2015, 54, 9298-9302.

(45) Peterson, M. L.; Hickey, M. B.; Zaworotko, M.; Almarsson, Ö. Expanding the Scope of Crystal Form Evaluation in Pharmaceutical Science. J. Pharm. Pharm. Sci. 2006, 9, 317-326.

(46) Morihiro, K.; Kasahara, Y.; Obika, S. Biological Applications of Xeno Nucleic Acids. Mol. BioSyst. 2017, 13, 235-245.

(47) Seela, F.; Peng, X.; Li, H. Base-Pairing, Tautomerism, and Mismatch Discrimination of 7Halogenated 7-Deaza-2‘-deoxyisoguanosine: Oligonucleotide Duplexes with Parallel and Antiparallel Chain Orientation. J. Am. Chem. Soc. 2005, 127, 7739-7751.

(48) Wempen, I.; Fox, J. J. Spectrometric Studies of Nucleic Acid Derivatives and Related Compounds. VI. On the Structure of Certain 5- and 6-Halogenouracils and -cytosines. J. Am. Chem. Soc. 1964, 86, 2474-2477.

(49) Privat, E. J.; Sowers, L. C. A Proposed Mechanism for the Mutagenicity of 5-Formyluracil. Mutation Res. 1996, 354, 151-156.

(50) Portalone, G.; Colapietro, M. An Unusual Syn Conformation of 5-Formyluracil Stabilized by Supramolecular Interactions. Acta Crystallogr., Sect. C: Cryst. Struct. Commun. 2007, 63, o650-o654. 
(51) Portalone, G. Solid-Phase Molecular Recognition of Cytosine Based on Proton-Transfer Reaction. Part II. Supramolecular Architecture in the Cocrystals of Cytosine and its 5Fluoroderivative with 5-Nitrouracil. Chem. Centr. J. 2011, 5, 51.

(52) Orozco, M.; Hernandez, B.; Luque, F. J. Tautomerism of 1-Methyl Derivatives of Uracil, Thymine, and 5-Bromouracil. Is Tautomerism the Basis for the Mutagenicity of 5Bromouridine? J. Phys. Chem. 1998, 102, 5228-5233.

(53) Jang, Y. H.; Sowers, L. C.; Çağin, T.; Goddard, W. A. III First Principles Calculation of pKa Values for 5-Substituted Uracils. J. Phys. Chem. A 2001, 105, 274-280.

(54) Chandra, A. K.; Uchimaru, T.; Zeegers-Huyskens, T. Theoretical Study on Protonated and Deprotonated 5-Substituted Uracil Derivatives and their Complexes with Water. J. Mol. Struct. 2002, 605, 213-220

(55) Wierzchowski, K. L.; Litonska, E.; Shuhar, D. Infrared and Ultraviolet Studies on the Tautomeric Equilibria in Aqueous Medium between Monoanionic Species of Uracil, Thymine, 5-Fluorouracil, and Other 2,4-Diketopyrimidines. J. Am. Chem. Soc. 1965, 87, 4621-4629.

(56) Abdrakhimova, G. S.; Ovchinnikov, M. Yu.; Lobov, A. N.; Spirikhin, L. V.; Ivanov, S. P.; Khurasan, S. L. 5-Fluororacil solutions: NMR study of acid-base equilibrium in water and DMSO. J. Phys. Org. Chem. 2014, 27, 876-883.

(57) Abdrakhimova, G. S.; Ovchinnikov, M. Yu.; Lobov, A. N.; Spirikhin, L. V.; Khurasan, S. L.; Ivanov, S. P. 5-Chlororacil and 5-bromouracil acid-base equilibrium study in water and DMSO by NMR spectroscopy. J. Mol. Struct. 2018, 1158, 51-56.

(58) Theruvathu, J. A.; Kim, C. H.; Darwanto, A. Neidigh, J. W.; Sowers, L. C. pH-Dependent Configurations of a 5-Chlorouracil-Guanine Base Pair. Biochemistry 2009, 48, 11312-11318. 
(59) Birnbaum, G. I.; Lin, T.-S.; Shiau, G. T.; Prusoff, W. H. A Novel Zwitterionic Structure and an Unusual Sugar Ring Conformation in 5-iodo-5'-amino-2',5'-dideoxyuridine, an Antiviral Nucleoside. J. Am. Chem. Soc. 1979, 101, 3353-3358.

(60) Lange, R. F. M.; Beijer, F. H.; Sijbesma, R. P.; Hoon, R. W. W.; Kooijman, H.; Spek, A. L.; Kroon, J.; Meijer, E. W. Crystal Engineering of Melamine-Imide Complexes; Tuning the Stoichiometry by Steric Hindrance of the Imide Carbonyl Groups. Angew. Chem. Int. Ed. 1997, 36, 969-971.

(61) Roth, B.; Strelitz, J. Z. Protonation of 2,4-Diaminopyrimidines. II. Dissociation Constants of 6-Aminoderivatives and anion Effects in Moderately Strong Acid. J. Org. Chem. 1970, 35, 26962702.

(62) Zhang, X.-L.; Chen, X.-M. Supramolecular Architectures and Helical Water Chains in Cocrystals of Melamine and Aromatic Carboxylic Acids. Cryst. Growth Des. 2005, 5, 617-622.

(63) Zhang, X.-L.; Ye, B.-H.; Chen, X.-M. Infinite Water Chains Trapped in an Organic Framework Constructed from Melamine with 1,5-Naphthalenedisulfonic Acid via Hydrogen Bonds. Cryst. Growth Des. 2005, 5, 1609-1616.

(64) Perpétuo, G. J.; Janczak, J. Supramolecular architectures in crystals of melamine and aromatic carboxylic acids. J. Mol. Struct. 2008, 891, 429-436.

(65) Vella-Zarb, L.; Braga, D.; Guy Orpen, G.; Baisch, U. The influence of hydrogen bonding on the planar arrangement of melamine in crystal structures of its solvates, cocrystals and salts. CrystEngComm 2014, 16, 8147-8159. 
(66) Perpétuo, G. J.; Janczak, J. Solid-state supramolecular architectures formed by cocrystallization of melamine and 2-, 3- and 4-fluorophenylacetic acids. J. Mol. Struct. 2018, 1152, 237-247.

(67) Abidi S. S. A.; Azim; Y.; Gupta, A. K.; Pradeep, C. P.; Cocrystals of indole-3-aetic acid and indole-3-butyric acid: Synthesis, structural characterization and Hirshfeld surface analysis. $J$. Mol. Struct. 2018, 1166, 202-213.

(68) Dudley, J. R. Cyanuric Chloride Derivatives. IX. Dissociation Constants of Substituted Melamines and Related Triazines. J. Am. Chem. Soc. 1951, 73, 3007-3008.

(69) Marchi-Artzner, V.; Artzner, F.; Karthaus, O.; Shimomura, M.; Ariga, K.; Kunitake, T.; Lehn, J.-M. Molecular Recognition between 2,4,6-Triaminopyrimidine Lipid Monolayers and Complementary Barbituric Molecules at the Air/Water Interface: Effects of Hydrophilic Spacer, Ionic Strength, and pH. Langmuir 1998, 14, 5164-5171.

(70) Purification of Laboratory Chemicals $6^{\text {th }}$ Ed., Armarego, W. L. F.; Chai, C., Eds.; Elsevier, $2009 ;$ p 380 .

(71) Aakeröy, C. B.; Despera, J.; Urbina, J. F. Supramolecular reagents: versatile tools for noncovalent synthesis. Chem. Commun. 2005, 2820-2822.

(72) Bhogala, B. R.; Basavoju, S.; Nangia, A. Tape and layer structures in cocrystals of some diand tricarboxylic acids with 4,4'-bipyridines and isonicotinamide. From binary to ternary cocrystals. CrystEngComm. 2005, 7, 551-562.

(73) Bhogala, B. R.; Basavoju, S.; Nangia, A. Three-Component Carboxylic Acid-Bipyridine Lattice Inclusion Host. Supramolecular Synthesis of Ternary Cocrystals. Cryst. Growth Des. 2005, 5, 1683-1686. 
(74) Bhogala, B. R.; Nangia, A. Ternary and quaternary co-crystals of 1,3-cis,5-ciscyclohexanetricarboxylic acid and 4,4'-bipyridines. New J. Chem. 2008, 32, 800-807.

(75) Moorthy, J. N.; Natarajan, P.; Venugopalan, P. Engineering of ternary co-crystals based on differential binding of guest molecules by a tetraarylpyrene inclusion host. Chem Commun. 2010, 46, 3574-3576.

(76) Tothadi, S.; Mukherjee, A.; Desiraju, G. R. Shape and size mimicry in the design of ternary molecular solids: towards a robust strategy for crystal engineering. Chem Commun. 2011, 47, 12080-12082.

(77) Seaton, C. C.; Blagden, N.; Munshi, T.; Scowen, I. J. Creation of Ternary Multicomponent Crystals by Exploitation of Charge-Transfer Interactions. Chem. Eur. J. 2013, 19, 10663-10671.

(78) Tothadi, S.; Desiraju, G. R. Designing ternary cocrystals with hydrogen bonds and halogen bonds. Chem Commun. 20113, 49, 7791-7793.

(79) Tothadi, S.; Sanphui, P.; Desiraju, G. R. Obtaining Synthon Modularity in Ternary Cocrystals with Hydrogen Bonds and Halogen Bonds. Cryst. Growth Des. 2014, 14, 5293-5302.

(80) Kodiah Beyeh, N.; Pan, F.; Rissanen, K. Hierarchical Ordering in Ternary Co-Crystals of C60, N-Benzyl Ammonium Resorcinarene Bromide and Solvent Molecules. Cryst. Growth Des. 2014, 14, 6161-6165.

(81) Adsmond, D. A.; Sinha, A. S.; Khandavilli, U. B. Rao; Maguire, A. R.; Lawrence, S. E. Design and Synthesis of Ternary Cocrystals Using Carboxyphenols and Two Complementary Acceptor Compounds. Cryst. Growth Des. 2015, 16, 59-69. 
(82) Topić, F. Rissanen, K. Systematic Construction of Ternary Cocrystals by Orthogonal and Robust Hydrogen and Halogen Bonds. J. Am. Chem. Soc. 2016, 138, 6610-6616.

(83) Bolla, G.; Nangia, A. Binary and ternary cocrystals of sulfa drug acetazolamide with pyridine carboxamides and cyclic amides. IUCrJ 2016, 3, 152-160.

(84) Allu, S.; Bolla, G.; Tothadi, S.; Nangia, A. Supramolecular Synthons in Bumetanide Cocrystals and Ternary Products. Cryst. Growth Des. 2017, 17, 4225-4236.

(85) Etter, M. C. Encoding and Decoding Hydrogen-Bond Patterns of Organic Compounds. Acc. Chem. Res. 1990, 23, 120-126.

(86) Aakeröy, C. B.; Beatty, A. M.; Helfrich, B. A. "Total Synthesis" Supramolecular Style: Design and Hydrogen-Bond-Directed Assembly of Ternary Supermolecules. Angew. Chem. Int. Ed. 2001, 40, 3240-3242.

(87) Branda, N.; Kurz, G.; Lehn, J.-M. JANUS WEDGES: a New Approach towards Nucleobase-Pair Recognition. Chem Commun. 1996, 2443-2444.

(88) Meena, D. C.; Sharma, S. K.; McLaughlin, L. W. Formation and Stability of a Janus-Wedge Type of DNA Triplex. J. Am. Chem. Soc. 2004, 126, 70-71.

(89) Artigas, G.; Marchán, V. Synthesis of Janus Compounds for the Recognition of G-U Mismatched Nucleobase Pairs. J. Org. Chem. 2013, 78, 10666-10677.

(90) Piao, X.; Xia, X.; Bong, D. Bifacial Peptide Nucleic Acid Directs Cooperative Folding and Assembly of Binary, Ternary, and Quaternary DNA Complexes. Biochemistry 2013, 52, 63136323. 
(91) Largy, E.; Liu, W.; Hasan, A.; Perrin, D. M. Base-Pairing Behavior of a Carbocyclic JanusAT Nucleoside Analogue Capable of Recognizing $A$ and $T$ within a DNA Duplex. ChemBioChem 2013, 14, 2199-2208.

(92) Largy, E.; Liu, W.; Hasan, A.; Perrin, D. M. A Pyrimidopyrimidine Janus-AT Nucleoside with Improved Base-Pairing Properties to both A and T within a DNA Duplex: The Stabilizing Effect of a Second Endocyclic Ring Nitrogen. Chem. Eur. J. 2014, 20, 1495-1499.

(93) Oxford Diffraction CrysAlis Software System, Oxford Diffraction LtD.; 2008.

(94) Farrugia, L. WinGX and ORTEP for Windows: an Update. J. Appl. Crystallogr. 2012, 45, 849-854.

(95) Burla, M. C.; Caliandro, R.; Camalli, M.; Carrozzini, B.; Cascarano, G. L.; De Caro, L.; Giacovazzo, C.; Polidori, G.; Spagna, R. SIR2004: an Improved Tool for Crystal Structure Determination and Refinement. J. Appl. Crystallogr. 2005, 38, 381-388.

(96) Sheldrick, G. M. A Short History of SHELX. Acta Crystallogr., Sect. A: Found. Crystallogr. 2008, 64, 112-122.

(97) Spek, A. Single-Crystal Structure Validation with the Program PLATON. J. Appl. Crystallogr. 2003, 36, 7-13.

(98) Macrae, C. F.; Bruno, I. J.; Chisholm, J. A.; Edgington, P. R.; McCabe, P.; Pidcock, E.; Rodriguez-Monge, L.; Taylor, R.; van de Streek, J.; Wood, P. A. Mercury CSD 2.0 - New Features for fhe Visualization and Investigation of Crystal Structures. J. Appl. Crystallogr. 2008, $41,466-470$.

(99) Nakanishi, K.; Suzuki, N.; Yamazaki, F, Ultraviolet Spectra of N-Heterocyclic Systems. I. The Anions of Uracils. Bull. Chem. Soc. Jpn. 1961, 34, 53-57. 
(100) Desiraju, G. R. A Bond by Any Other Name. Angew. Chem. Int. Ed. Engl. 2011, 50, 52-59.

(101) Childs, S. L.; Stahly, G. P.; Park, A. The Salt-Cocrystal Continuum: The Influence of Crystal Structure on Ionization State. Mol. Pharmaceutics 2007, 4, 323-338.

(102) Portalone, G.; Colapietro, M. Solid-phase Molecular Recognition of Cytosine based on Proton-Transfer Reaction. J. Chem. Crystallogr. 2009, 39, 193-200.

(103) Portalone, G. Supramolecular Association in Proton-Transfer Adducts Containing Benzamidinium Cations. (I). Four Molecular Salts with Uracil Derivatives. Acta Crystallogr., Sect. C: Cryst. Struct. Commun. 2010, 66, o295-o301.

(104) Portalone, G. Redetermination of 5-Iodouracil. Acta Crystallogr., Sect. E: Cryst. Struct. Rep. Online 2008, 64, o365.

(105) Barnett, S. A.; Hulme, A. T.; Issa, N.; Lewis, T. C.; Price, L. S.; Tocher, D. A.; Price, S. L. The Observed and Energetically Feasible Crystal Structures of 5-Substituted Uracils. New J. Chem. 2008, 32, 1761-1775.

(106) Auffinger, P.; Hays, F. A.; Westhof, E.; Ho, P. S. Halogen Bonds in Biological Molecules. Proc. Natl. Acad. Sci. U.S.A. 2004, 101, 16789-16794.

(107) Scholfield, M. R.; Vander Zanden, C. M.; Carter, M.; Ho, P. S. Halogen Bonding (Xbonding): A Biological Perspective. Protein Sci. 2013, 22, 139-152. 
For Table of Contents Use Only

\section{Multifacial Recognition in Binary and Ternary Cocrystals from 5-Halouracil and Aminoazine Derivatives}

Gustavo Portalone and Kari Rissanen

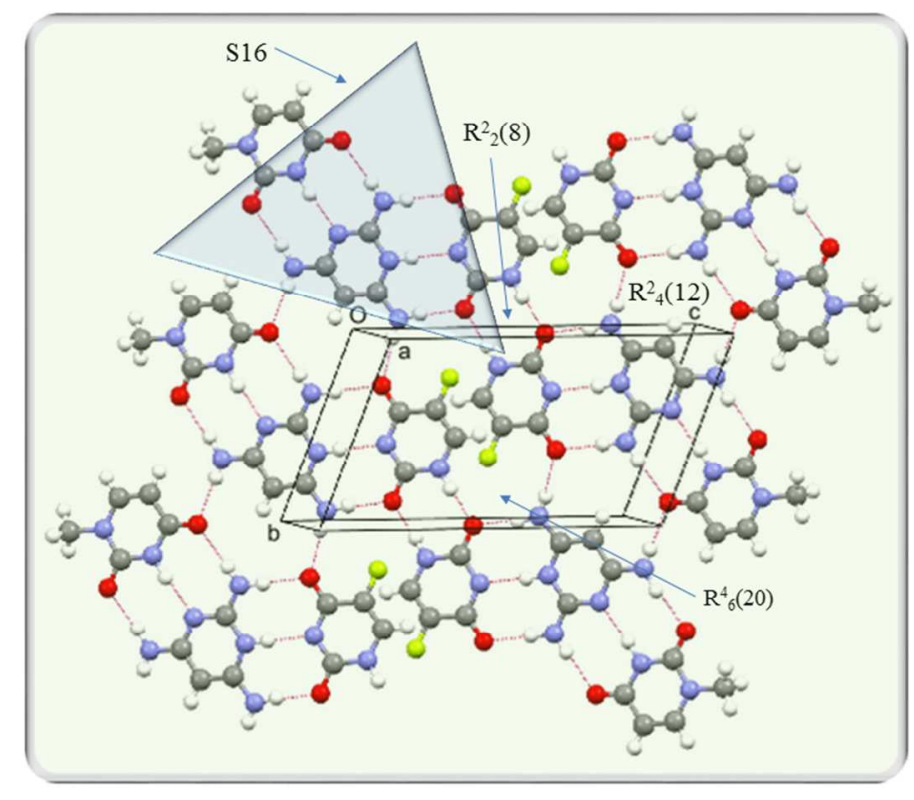

Twelve new binary cocrystals containing uracil or 1-methyluracil with halide modification at the 5 position, coupled with a 2-aminoadenine simulants (aminoazines), have been studied by X-ray diffraction. Moreover, the first single crystal X-ray diffraction study of a ternary cocrystal based on the JANUS-WEDGE concept and containing the 5-fluorouracil/2,4,6-triamino pyrimidine/1methyluracil $(1: 1: 1)$ triad has been reported. 